\title{
ORGANIZACIONES POPULARES DE VIVIENDA: ALTERNATIVA AL DÉFICIT DE VIVIENDA ADECUADA EN COLOMBIA. Estudio comparativo de caso OPV ASOVIVIR con MISN Ciudad Verde.
}

\author{
Juan Carlos Castellanos Puentes \\ Profesionales Asociados para el Desarrollo Urbano y Regional (PROADECUAR) \\ Director del trabajo de grado: Carlos Alberto Torres Tovar \\ jccastellanosp@unal.edu.co
}

\section{RESUMEN}

Este trabajo busca indagar sobre las opciones de las Organizaciones Populares de Vivienda para brindar alternativas de acceso a la vivienda adecuada en Colombia (en concordancia con el Pacto de Derechos Sociales Económicos y Culturales), a partir de la comparación entre "Ciudad Verde" en Soacha, el mayor Macroproyecto de Interés Social Nacional (con una producción cercana a 50 mil unidades) y la Asociación de Vivienda Integral ASOVIVIR, que a principios de los 90 construyó 550 viviendas unifamiliares a través de un proceso autogestionario y a partir de la cual se dio origen a la Federación de Vivienda Popular FENAVIP que desarrolló más de 20.000 viviendas en el país, con ciertas ventajas diferenciales frente a la producción de los agentes inmobiliarios con ánimo de lucro, con quienes el Gobierno Nacional desarrolla los Macroproyectos, facilitando la adecuación masiva de suelo para vivienda social pero sin generar unidades habitacionales completamente adecuadas a las necesidades de sus habitantes.

Palabras clave: Autogestión, vivienda adecuada, macroproyectos.

\begin{abstract}
This paper seeks to investigate the options of Popular Housing Organizations to provide alternatives for access to adequate housing in Colombia (according to the Economic and Cultural Social Rights pact), based on the comparison between "Green City" in Soacha , The largest Macroproject of National Social Interest (with a production of about 50 thousand units) and the Association of Comprehensive Housing ASOVIVIR, which in the early 1990s built 550 single-family homes through a self-management process and gave rise to the Housing Federation Popular FENAVIP that developed more than 20,000 houses in the country, with certain differential advantages compared to the production of real estate agents for profit, with whom the National Government develops the Macroprojects, facilitating the massive adaptation of land for social housing but without generating housing units completely adequate to the needs of its inhabitants.
\end{abstract}

Key words: Self-management, adequate housing, macro-projects 


\section{POLÍTICAS PÚBLICAS PARA LA PRODUCCIÓN VIVIENDA SOCIAL}

Aunque el concepto de vivienda social (VS) nace asociado a la respuesta estatal frente a la demanda de vivienda del proletariado con la industrialización en Europa y Estados Unidos (Hall, 1996), el concepto de vivienda social ha sido transformado a lo largo del siglo XX y a partir de esto se han modificado las políticas en la materia.

El Banco Mundial ente 1970 y 1990 realizó cambios en la política habitacional; mientras en la primera década su objetivo era implementar proyectos de vivienda para los pobres mediante tierra asequible para recuperar costos (donde el Estado era directamente el proveedor); en los ochenta el Banco buscaba generar intermediarios financieros para los créditos hipotecarios autosuficientes y reestructurar los subsidios habitacionales (el Estado pasa de benefactor a regulador). Para los noventa el objetivo fue crear un sector habitacional que atendiera las necesidades de los consumidores, productores, financistas, gobiernos y promoviera el desarrollo económico (Torres, 2009: 55); el Estado continuó con su función reguladora pero en su tarea de garantizar el desarrollo económico debía facilitar la operación de los agentes económicos fijándole responsabilidades frente a las condiciones mínimas de la vivienda que terminan siendo las máximas ofrecidas por el constructor.

Ante el retiro del aparato de Estado de la producción de vivienda, se transfiere esta función a entidades subnacionales $u$ organismos especializadas mediante subsidios y se asume la regulación del mercado inmobiliario para garantizar la satisfacción del derecho en condiciones adecuadas; pero desafortunadamente los resultados son insuficientes en cuanto las características del bien y los servicios conexos. Aunque los gobiernos han adoptado diversas políticas habitacionales, estas han sido insuficientes para garantizar plenamente el derecho a la vivienda adecuada a familias de menores ingresos, en términos de cantidad y calidad. Bajo formas capitalistas de producción de la vivienda, mediadas exclusivamente por el mercado, se mantienen y en ocasiones se incrementa el déficit cuantitativo y cualitativo.

La dinámica del mercado, para generar mayor utilidad, distribuye los suelos de baja calidad (por ubicación, infraestructura y exposición a riesgos) a los sectores de menores ingresos, los cuales acceden a las soluciones habitaciones, principalmente a través de procesos de desarrollo progresivo (Turner, 1976). La vivienda social que surge de estos procesos presenta grandes falencias en términos cuantitativos y sobre todo cualitativos que se van satisfaciendo también de manera progresiva, producto del trabajo social y/o de la intervención estatal.

\section{$1.1 \quad$ Déficit de vivienda}

El déficit no solo corresponde al número insuficiente de unidades para atender toda la población que necesita acceder a este derecho (déficit cuantitativo), también incluye las falencias en la calidad de las viviendas que no permiten la completa satisfacción del derecho (déficit cualitativo); ONU Hábitat desarrolló una metodología para la evaluación del déficit en Colombia, el cuantitativo se determina por estructura, cohabitación y hacinamiento no mitigable. El déficit de estructura corresponde a viviendas sin paredes o construidas con materiales inestables; la cohabitación se refiere a la convivencia de varios núcleos familiares en la misma vivienda; el hacinamiento no mitigable corresponde a hogares en los cuales habitan cuatro o más personas por cuarto.

El déficit cualitativo es el número de viviendas que requieren mejoramiento, ampliación o dotación de servicios públicos, por encontrarse en condiciones no aptas para la habitabilidad en: Estructura (construidas con material estable pero con pisos en tierra o arena. Hacinamiento mitigable (hogares con más de dos y menos de cuatro personas por cuarto). Servicios públicos (ausencia de conexión a acueducto, alcantarillado o a pozo séptico; sin servicio de energía eléctrica o sin recolección de basuras).

Para Leilani Farha relatora especial sobre una vivienda adecuada de las Naciones Unidas las causas estructurales comunes de la falta de hogar son las siguientes:

"a) La retirada de todos los niveles de gobierno de la protección social y la vivienda social y la privatización de los servicios, la infraestructura, la vivienda y el espacio público;

b) El abandono de la función social de la tierra y la vivienda;

c) El hecho de no abordar las crecientes desigualdades en los ingresos, la riqueza y el acceso a la tierra y la propiedad; 
d) La adopción de políticas fiscales y de desarrollo que apoyan la desregulación y la especulación inmobiliaria e impiden el desarrollo de opciones de vivienda asequible..." (Farha. 2015: 22).

\subsection{Vivienda adecuada}

La vivienda fue reconocida como parte del derecho a un nivel de vida adecuado en la Declaración Universal de Derechos Humanos de 1948, lo cual fue ratificado en 1966 a través del Pacto Internacional de Derechos Económicos, Sociales y Culturales - PIDESC. En el marco del Hábitat II, (Estambul, 1996), se fija el objetivo de garantizar el derecho a la vivienda adecuada. En el 2000 el Consejo de Derechos Humanos de la Organización de las Naciones Unidas, creó el Relator Especial sobre una vivienda adecuada como elemento integrante del derecho a un nivel de vida digna, con la tarea de hacer seguimiento al acceso a la vivienda adecuada.

Mediante la Ley 74 de 1968, el Estado Colombiano suscribe el PIDESC, así como el Protocolo Facultativo de este, incorporando el derecho a la vivienda adecuada consagrado en el primer párrafo del artículo. $11^{\circ}$ del Pacto, mediante el cual se establece que los Estados "reconocen el derecho de toda persona a un nivel de vida adecuado para sí y su familia, incluso alimentación, vestido y vivienda adecuados"

La Asamblea General de la ONU convocó en 1976 la primera Conferencia Mundial sobre Asentamientos Humanos (Hábitat I), en la que se promulgó la Declaración de Vancouver en la cual se reconoce que las condiciones de los asentamientos humanos impactan en el desarrollo humano, social y económico además que el crecimiento urbano descontrolado afecta negativamente al ambiente; para enfrentar los desafíos del crecimiento rápido y descontrolado de las ciudades se formula el Plan de Acción de Vancouver, cambiando la visión del concepto tradicional de vivienda por un enfoque integral, que incorpora la vivienda y su entorno, con sus dimensiones políticas, espaciales, sociales, culturales, económicas y ambientales, La conferencia promueve un nuevo enfoque de las políticas públicas de vivienda que contemplan el uso y tenencia del suelo, la infraestructura y los servicios básicos de acuerdo con las necesidades de las poblaciones, quienes tienen el deber y el derecho de participar en las decisiones sobre sus asentamientos humanos ${ }^{1}$

Las "directrices para la acción", de la declaración de Vancouver, establecen que la vivienda y los servicios adecuados son un derecho humano básico que impone a los gobiernos la obligación de promover su acceso prioritario a través de programas de auto ayuda y acción comunitaria, las políticas eficaces de asentamientos humanos requieren de colaboración continua entre gobierno y comunidades, pues el objetivo del diseño de los asentamientos humanos es preservar la identidad de individuos familias y sociedades.

En 1991, durante el sexto período de sesiones, el Comité de DESC formula la Observación General No. 4, la cual plantea que para que la vivienda sea adecuada, debe reunir como mínimo los siguientes criterios:

- Seguridad de la tenencia, que garantice protección jurídica contra el desalojo forzoso, el hostigamiento y otras amenazas.

- Disponibilidad de servicios, materiales, instalaciones e infraestructura, como agua potable, instalaciones sanitarias adecuadas, energía para la cocción, la calefacción y el alumbrado, y conservación de alimentos además de la eliminación de residuos.

-Asequibilidad económica, que no dificulte el disfrute de otros derechos humanos.

- Habitabilidad, que garantice seguridad y protección contra el frío, la humedad, el calor, la lluvia, el viento u otros riesgos para la salud y la vida.

- Accesibilidad, en consideración a las necesidades específicas de los grupos desfavorecidos y marginados.

- Ubicación, que ofrezca acceso empleo, servicios de salud, escuelas, guarderías y otros servicios lejos de zonas contaminadas o peligrosas.

•Adecuación cultural, que tome en cuenta y respete la expresión de la identidad cultural".

En concordancia con el PIDESC, el artículo 51 de la Constitución Política de Colombia, consagra "todos los colombianos tiene derecho a vivienda digna. El Estado fijará las condiciones necesarias para hacer efectivo este derecho y promoverá planes de vivienda de interés social, sistemas adecuados de financiación a largo plazo y formas asociativas de ejecución de estos programas de vivienda", aunque se troca el concepto de vivienda

\footnotetext{
1 Puede ver la declaración completa http://biblio.juridicas.unam.mx/libros/1/353/61.pdf
} 
adecuada por el de vivienda digna; la Corte Constitucional mediante sentencia T-583/13, magistrado Nilson Pinilla Pinilla consagra el "derecho fundamental a la vivienda digna o adecuada".

Expresa la Corte. "Carecer las personas de un lugar decoroso de habitación, les impide sobrellevar la pervivencia con intimidad, autoestima, conformación familiar y protección, además de conllevar adicionales riesgos contra la salud a consecuencia de la intemperie". Y agrega que la vivienda digna "debe comprender la posibilidad real de gozar de un espacio material delimitado y exclusivo, en el cual la persona y su familia puedan habitar y llevar a cabo los respectivos proyectos de vida, en condiciones que permitan desarrollarse como individuos dignos, integrados a la sociedad". La sentencia consigna que: la "dignidad" en el disfrute real de la vivienda no se reduce a una concepción ideal, pues involucra la noción de "habitabilidad", en condiciones de salubridad, funcionalidad, privacidad y seguridad, comportando responsabilidad de calidad, estabilidad y titularidad por parte del Estado y los urbanizadores. (CCC. 2013). Con esta definición se incorporan los elementos de seguridad de la tenencia, disponibilidad de servicios, asequibilidad y habitabilidad, pero no se hace tangible la ubicación, ni la consideración a las necesidades específicas de los grupos desfavorecidos y marginados ni mucho menos la adecuación cultural, con lo cual el derecho a la vivienda en Colombia se restringiría en varios atributos de la vivienda adecuada.

Además de esta reducción de atributos, agrega la Corte que el derecho fundamental a la vivienda digna está sujeto a un criterio de progresividad en su cobertura, su ejecución sigue parámetros de justicia distributiva, "debiendo priorizarse cuándo se requiera con mayor apremio, por razones de edad (niñez, senectud), embarazo y discapacidad, entre otras". En concordancia con la sentencia la provisión de vivienda de interés prioritaria se ha concentrado en la población más vulnerable, fundamentalmente los desplazados por la violencia, pero esta vivienda en la mayoría de los casos no contempla la adecuación cultural a las características de los beneficiarios y esta priorización va en contravía de lo consagrado en el párrafo 2 del artículo 2 del PIDESC, que establece el disfrute del derecho sin forma alguna de discriminación, pues precisamente como lo señala el Comité DESC en su Observación General № 2 (1990), las obligaciones de los Estados son quizás más pertinentes durante tiempos de contracción económica.

En la conferencia en Estambul de 1996 (Hábitat II), se suscribió la "Agenda Hábitat", que establece el compromiso de promover la vivienda adecuada y los asentamientos humanos seguros, salubres, habitables, equitativos, sustentables y productivos. La agenda hábitat contempla no solo la vivienda como unidad individual sino los asentamientos en su dimensión física (vivienda y entorno), reconociendo que para lograr el pleno ejercicio del derecho a una vivienda adecuada, los mercados deben funcionar con eficiencia y responsabilidad social y ambiental, se requiere la combinación de esfuerzos de comunidades, gobiernos locales y entidades privadas. Los gobiernos participantes en la conferencia, reconocieron el deterioro de las condiciones de los asentamientos humanos y la vivienda, especialmente en países "en vías de desarrollo" y establecieron como objetivos asegurar vivienda adecuada para todos y garantizar el desarrollo adecuado de los asentamientos humanos.

La Agenda de Hábitat II estableció, que dentro de los sistemas de suministro de vivienda, los Estados debían facilitar el funcionamiento de los mercados, así como la producción de viviendas por las comunidades. Se consideró en ese momento que la eficiencia y eficacia el mercado eran importantes para alcanzar la meta del desarrollo sostenible y por lo tanto los gobiernos debían facilitar el buen funcionamiento del mercado de la vivienda e intervenirlo de ser necesario. Con respecto a la producción de vivienda por las comunidades, la declaración reconoce en el numeral 73 que: "(...) especialmente [en] países en desarrollo, más de la mitad del patrimonio de viviendas existente ha sido construido por los propios dueños ocupantes, principalmente en el sector de población de ingresos más bajos. La construcción de la propia vivienda seguirá teniendo durante mucho tiempo un papel fundamental [...]. Muchos países están prestando apoyo a este medio de construcción de viviendas por medio de programas de regularización y mejora."

Por lo anterior se sugiere dentro de las medidas, "fomentar el papel de las organizaciones comunitarias y no gubernamentales en la asistencia y facilitación de la producción de viviendas construidas por los propios interesados" (numeral 74 declaración hábitat III) y garantizar el acceso a la tierra como condición estratégica para la vivienda adecuada. El alto comisionado de las Naciones Unidas para los derechos humanos, en el folleto sobre vivienda adecuada (2010), citando la Estrategia Mundial de Vivienda reconoce que "muchas de las medidas requeridas para promover el derecho a la vivienda requieren sólo la abstención del gobierno de ciertas prácticas y un compromiso para facilitar la autoayuda de los grupos afectados." Es decir que la solución no depende 
exclusivamente de la disponibilidad de recursos estatales, pues la autoayuda puede contribuir a la solución de las falencias además los recursos de cooperación internacional, pueden contribuir a la autoproducción

Ante el déficit de vivienda Leilani Farha, relatora especial sobre una vivienda adecuada como elemento integrante del derecho a un nivel de vida adecuado, en su Informe al Consejo de Derechos Humanos del 30 de diciembre de 2015, considera que aunque dentro de los Objetivos Desarrollo del Milenio está asegurar, para 2030, el acceso de todas las personas a viviendas y servicios básicos adecuados, seguros y asequibles:

"la falta de hogar es una crisis mundial de derechos humanos directamente relacionada con el aumento de la desigualdad en la riqueza y la propiedad (...) se debe a la incapacidad de los Estados para dar respuesta tanto a las circunstancias individuales como a una serie de causas estructurales, abandonando la responsabilidad de la protección social y permitiendo que la especulación y la inversión inmobiliarias no reguladas excluyan a un número creciente de personas de todo tipo de vivienda (...) La falta de hogar se produce cuando la vivienda se trata como una mercancía y no como un derecho humano.." (Farha. 2015: 5). Reitera la relatora que desde un enfoque de derechos humanos debe reconocerse como actores del cambio a las personas carentes de hogar y permitírseles que estas mismas definan sus necesidades y hagan parte de las soluciones para una vivienda adecuada. Atribuye como causas de la falta de hogar entre otros a la ineficiencia en la regulación de los mercados financieros y a la especulación sobre la tierra y los inmuebles que dan como resultado la vivienda precaria, los asentamientos informales o la ubicación en zonas remotas, insuficientemente atendidas, donde no hay trabajo ni suficientes las personas son privadas de las oportunidades económicas y redes sociales.

A partir de las recomendaciones de la relatora especial la Asamblea General del Consejo de Derechos Humanos de la ONU, en sesión del 18 de marzo de 2016, de cara a Hábitat III y la Nueva Agenda Urbana, exhorta a la aplicación de la Agenda 2030 para el Desarrollo Sostenible, que con la meta 11.1 busca asegurar el acceso de todas las personas a viviendas y servicios básicos adecuados, e insta a los Estados a adoptar estrategias intersectoriales inclusivas que respeten, protejan y hagan efectivos los derechos humanos de todos, en especial de las personas más vulnerables. ${ }^{2}$

\section{POLÍTICAS HABITACIONALES EN COLOMBIA A PARTIR DEL CONSENSO DE WASHINGTON}

Con la aprobación de la Ley $3^{\text {a }}$ de 1991 y la expedición de una nueva Constitución Política, se genera un nuevo marco jurídico para la vivienda social. Con la Ley $3^{\underline{a}}$ se crea el Sistema Nacional de Vivienda de Interés Social, a través del cual se sustituye al Estado como constructor de viviendas y proveedor de créditos, dejando la responsabilidad de provisión de vivienda al "mercado", vinculando a las cajas de Compensación Familiar y concentrando la función del Estado en la administración y entrega de subsidios.

Con el Plan Nacional de Desarrollo 2006-2010, además del subsidio a la tasa de interés, se incorpora a la política de vivienda la generación masiva de suelo, a través del desarrollo de macro-proyectos de vivienda de interés social nacional - MISN en suelo rural o semirural que se declara urbano. Así se facilita el acceso a suelo para que los desarrolladores inmobiliarios puedan ofertar vivienda para la población de menores ingresos.

El Plan Nacional de desarrollo 2010-2014, denominado "Prosperidad para Todos" da continuidad a los MISN y se propone la entrega de vivienda totalmente gratis para el usuario, pero pagada a los constructores privados con cargo a los recursos públicos (cuatro billones de pesos), con lo cual pareciera que se volviera a la condición de estado benefactor, sin embargo dado que las 100 mil viviendas ofertadas no cubren el déficit total, la escogencia de los beneficiarios está sometida a la presión de los actores políticos. En el marco del Plan, se expide la Ley 1537 de 2012, "por la cual se dictan normas tendientes a facilitar y promover el desarrollo urbano y el acceso a la vivienda", que tiene por objeto señalar competencias, responsabilidades y funciones de las entidades nacionales y territoriales, además la confluencia del sector privado en el desarrollo de Vivienda de Interés Social y Vivienda de Interés Prioritario, así como "incentivar el sistema especializado de financiación de vivienda", se fija el subsidio a la oferta. Con este reciente viraje se impulsa más la participación del sector privado en la producción

\footnotetext{
${ }^{2}$ Puede verse el documento completo en https://documents-dds-ny.un.org/doc/ UNDOC/LTD/G16/ 054/94/PDF/G1605494.pdf?OpenElement
} 
inmobiliaria y con la "confluencia del sector privado" se evidencia una vez más la simbiosis entre gobernantes y constructores, en la cual la administración termina trasladando las decisiones urbanísticas a la iniciativa privada, sin un plan eficiente de desarrollo integral del territorio, promoviendo ocupación de predios en zonas periféricas de las ciudades (donde el suelo es más barato y la plusvalía del suelo es apropiada por el propietario del suelo y/o el constructor).

Dado que la política de vivienda en Colombia ha estado imbricada con el interés privado, puede explicarse porque la concepción estatal de la vivienda social está mediada principalmente por el precio de las unidades inmobiliarias, es decir se conciben por su valor de cambio y no por su valor de uso; en beneficio principal de la acumulación de capital de los agentes relacionados con la construcción y financiación para garantizar la vivienda (Harvey 1977: 159-199. Jaramillo, 1979: 65-120. Pradilla 1987: 17-22) y en perjuicio de la producción social de vivienda y hábitat

\subsection{Las Organizaciones Populares de Vivienda}

Mediante la Ley $9^{a}$ de 1989 se definieron las competencias municipales, cesiones urbanísticas, bancos de tierras, instrumentos financieros y la extinción de dominio; defendiendo el interés general sobre el particular, se consagra la función social de la propiedad. En este contexto, se reconoce en la ley a las OPV.

Aunque la gestión colectiva de vivienda y hábitat existía antes de la Ley 9a de 1989, en el artículo 62 de esta se reconoció la existencia de las Organizaciones Populares de Vivienda, como organizaciones sociales sin ánimo de lucro, cuyo sistema financiero es la economía solidaria con el fin de desarrollar "programas de vivienda para sus afiliados por sistemas de autogestión o participación comunitaria". Pueden ser por ejemplo asociaciones, fundaciones, corporaciones, sindicatos, cooperativas, fondos de empleados o juntas de acción comunal.

Los planes habitacionales de estas, "deben ejecutarse en terrenos aptos para el desarrollo urbano y de conformidad con todas las normas técnicas, urbanísticas y arquitectónicas." y eso las diferencia de otras organizaciones de gestión de vivienda, como las de invasión o urbanización ilegal. Se concibe a las OPV, como un mecanismo de participación ciudadana, para el desarrollo de funciones y servicios a cargo de los municipios, y para esto se les faculta para celebrar convenios, acuerdos o contratos con las entidades estatales. El reconocimiento de las OPV, es una estrategia del gobierno nacional, para producir vivienda formal de bajo costo, vinculando la mano de obra y el trabajo de los futuros pobladores, incorporando las prácticas de la autoconstrucción y el desarrollo progresivo, que se aplican en los procesos informales. Se incorpora la autogestión colectiva a la producción de vivienda formal, mediante un esquema cooperativo, combinando la autogestión con la intervención de la administración pública; desde su reconocimiento las OPV han generado algunas experiencias exitosas en calidad edificatoria y hábitat, pero con relativa baja producción de unidades.

Mediante el Decreto 2391 de 1989, que reglamenta el artículo 62 de la ley 9a y el artículo 3ํㅡㄹ del Decreto Ley 78 de 1987, (el cual asigna a los municipios las actividades de control y vigilancia de los programas de vivienda), se definen varios elementos para el desarrollo de las actividades de las Organizaciones Populares de Vivienda así: - Sistema financiero de economía solidaria: Aquel en el cual todos los afiliados participan directamente mediante aportes en dinero y/o en trabajo comunitario.

- Sistemas de Autogestión o Participación Comunitaria: Cuando en un plan de construcción, adecuación o mejoramiento de vivienda por autogestión o participación comunitaria, participan todos los afiliados administrativa, técnica y financieramente.

- Modalidades de los Sistemas de Autogestión o Participación Comunitaria:

- Por Construcción Delegada: La gestión, administración y planificación de la obra, así como el nombramiento del personal técnico administrativo está a cargo de los afiliados a la OPV, sin trabajo comunitario en la ejecución de las obras.

- Autoconstrucción: Los afiliados contribuyen directamente con trabajo en la ejecución de las obras.

A Mayo de 2014 en la capital de Antioquia existía un total de 45 OPV activas, las cuales estaban constituidas no solo para la gestión de vivienda nueva sino para mejoramiento de barrios, y estaban apoyadas por la administración municipal, con recursos y acompañamiento en sus gestiones. A Junio del mismo año había 363 OPV registradas en tres Cámaras de Comercio del departamento de Boyacá. A Diciembre de 2016 en Bogotá existían 23 OPV que están agremiadas en el Comité Central de Victimas por una Vivienda Digna y ante la Secretaria de Hábitat se encontraban inscritas 10 organizaciones, las cuales pueden enajenar inmuebles, es decir 
están facultados para captar recursos y realizar negocios inmobiliarios, una de ellas, la Corporación Promotora de Vivienda y Desarrollo Ecológico de Colombia - CORPROVICOL, ubicada también en la localidad de Bosa fue intervenida en Junio de 2015 para salvaguardar los recursos de hogares afiliados, otra ubicada en el Porvenir tiene la asignación del predio por reubicación de familias que estaban en zona de alto riesgo físico, pero como no habia podido realizar el cierre financiero por lo tanto el proceso está acompañado por la Caja de Vivienda Popular.

Las principales dificultades de las OPV están en la gestión del suelo, en la consecución de recursos para complementar el subsidio y en la inexperiencia administrativa, ante la ausencia de un ente promotor y de programas de formación que debería ser "suministrada por el Servicio Nacional de Aprendizaje, la Escuela Superior de Administración Pública y/o por las entidades públicas y privadas interesadas en tal fin" (artículo 13. Decreto 2391 de 1989). Hay algunas experiencias exitosas de producción asociativa que deben evaluarse como alternativa ante el fracaso del modelo neoliberal que además de insostenible e inequitativo puede colapsar, como lo acaecido con la burbuja inmobiliaria de España, tal como lo reconoció Ada Colau, alcaldesa de Barcelona, en el V Congreso de Ciudades y Gobiernos Locales Unidos realizado en Bogotá en Octubre de 2016.

\section{EVALUACIÓN DE LAS DIFICULTADES Y POTENCIALIDADES DE LA OPV ASOVIVIR}

Una experiencia significativa en Bogotá, ha sido la de la Asociación para la Vivienda Integral - ASOVIVIR, que con 550 viviendas se convirtió en modelo de gestión para otras organizaciones en Colombia; por lo anterior es pertinente difundir esta experiencia en otros países del mundo. ASOVIVIR es una de las primeras OPV que se establecieron en Bogotá, impulsada por guerrilleros desmovilizados del Movimiento 19 de Abril (M-19); en el año 1993 la organización adquirió un terreno ubicado en la localidad de Bosa que era propiedad estatal (ICT)

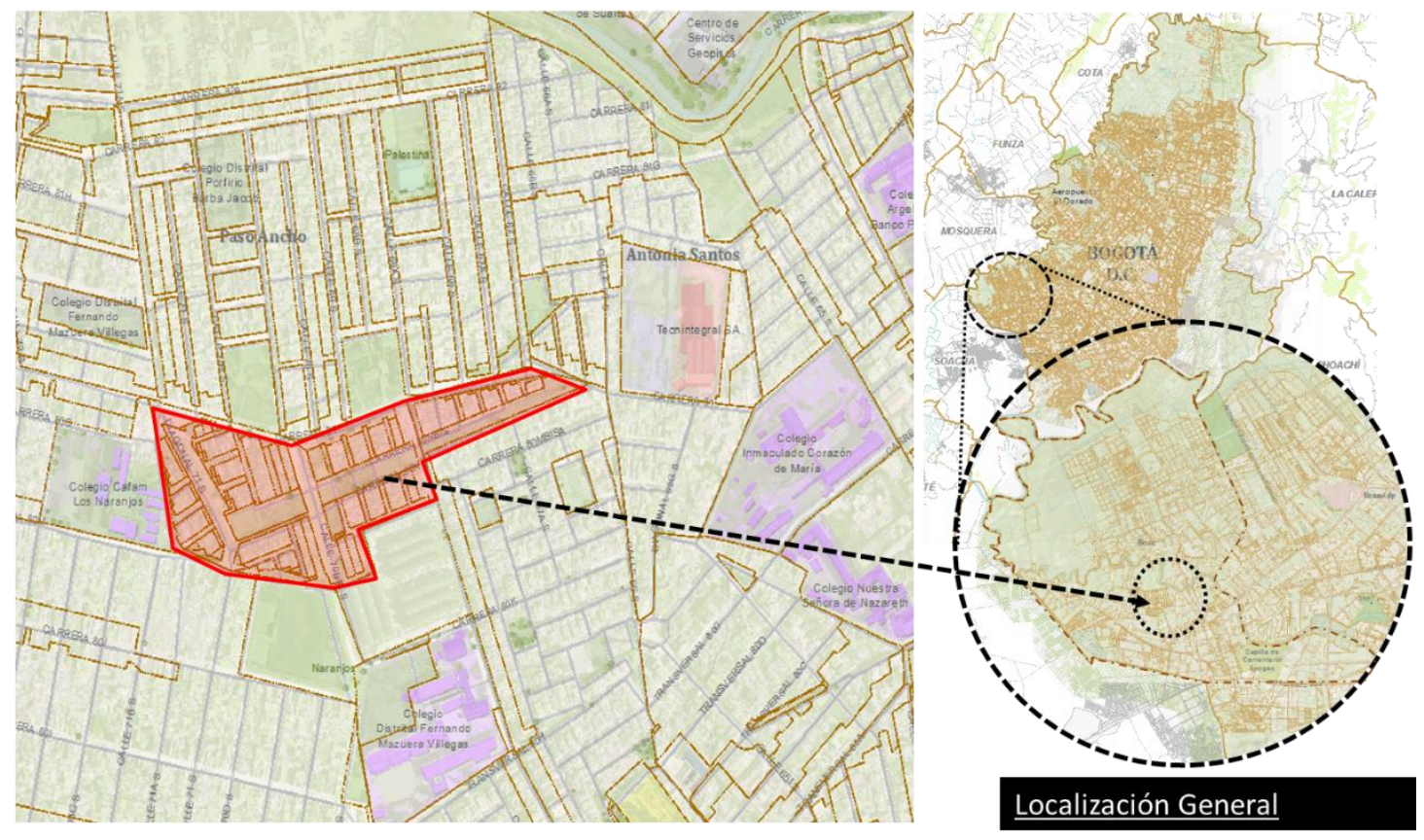

Ilustración 1 Ubicación del proyecto.

En el plano de la derecha, la ubicación de la localidad de Bosa, en el límite suroccidente de Bogotá, a la izquierda, en el corazón de la localidad, ASOVIVIR.

\subsection{El marco normativo, jurídico y político}

En 1987 a la Coordinadora Nacional Guerrillera, que había sido conformada inicialmente por el M-19, el Comando Ricardo Franco de las FARC y el Movimiento Armado Quintín Lame, se sumó las FARC, el EPL y el Ejército de Liberación Nacional (ELN) para integrar la Coordinadora Guerrillera Simón Bolívar con el propósito de realizar 
acciones armadas conjuntas y desarrollar un proceso articulado de negociación con el gobierno en cabeza de Virgilio Barco Vargas presidente de la república en el periodo 1986 -1990. En proceso de negociaciones, se expide el enero la Ley 9a de 1989 y el 2 de noviembre del mismo año se suscribe con el M-19 bajo la comandancia de Carlos Pizarro, el "Pacto Político por la Paz y la Democracia", el cual se ratifica el día 9 de marzo de 1990 con el acto de la entrega de armas y la firma del "Acuerdo político entre el Gobierno Nacional, los partidos políticos, el M-19 y la Iglesia Católica en calidad de tutora moral y espiritual del proceso"

Producto del proceso de paz con el M-19 surge un nuevo movimiento político que lanza como candidato a la presidencia a Pizarro, el cual es asesinado el 26 de abril del mismo año; a pesar del asesinato de su dirigente, la guerrilla recién desmovilizada continúa con los compromisos, entre estos el impulso a una nueva Constitución Política; antes de la promulgación de la nueva Constitución; dentro de las primeras normas que se aprueban luego del pacto nacional con el M-19, se expiden en enero de 1991 las leyes $2^{\underline{a}}$ y $3^{\text {a }}$, que modifican la Ley $9^{\underline{a}}$ de 1989, siendo la Ley 3ํㅡ el marco jurídico del Sistema Nacional de Vivienda de Interés Social.

En honor al comandante asesinado, se constituye la Asociación de Viviendistas Carlos Pizarro, en el marco de lo regulado por la Ley 9aㅡ de 1989 para las Organizaciones Populares de Vivienda. Una vez seleccionado un predio ubicado en Bosa una localidad periférica de Bogotá, de propiedad del Instituto de Crédito Territorial en proceso de liquidación, se procedió a constituir legalmente la OPV ASOVIVIR y establecer el compromiso de compraventa del lote. Posteriormente la Asociación participó de la constitución de la Federación Nacional de Vivienda Popular FENAVIP que impulsó la creación de otras OPV, entre estas La Esperanza en la misma localidad de Bosa, en la cual se desarrollaron 1.500 viviendas unifamiliares y otras en las ciudadelas El Recreo y El Porvenir, cuando el fundador de la Asociación Carlos Pizarro, Germán Ávila, fue gerente de METROVIVIENDA.

\subsection{Gestión económica}

Para ser parte de la organización, las familias debían hacer una inscripción con el pago de una cuota única de afiliación, destinada a gastos administrativos y adicionalmente se abría una cuenta en una misma entidad cooperativa de ahorro y crédito, la cual prestaba a cada familia hasta cuatro veces el valor de sus ahorros para el pago del suelo, pues como se dijo anteriormente el lote se entregó para ser pagado a crédito.

Parte del préstamo realizado para el pago del terreno, se invirtió en el urbanismo y la construcción; como estrategia de financiación la OPV constituyó su propia entidad cooperativa de ahorro y crédito, la cual se denominó CREAR Cooperativa, y a través de esta se suministraron los recursos adicionales para la construcción de las viviendas mediante préstamos individuales a los asociados.

Además de los aportes en dinero, los viviendistas participaban con su trabajo comunitario, cada fin de semana, el cual complementaba el trabajo calificado que era desarrollado entre semana por obreros, entre los cuales se contrataba a algunos asociados con experiencia en construcción. La gestión administrativa, técnica y financiera se realizaba por los dirigentes de la OPV quienes recibían una remuneración por ello y además había funcionarios contratados, dentro de los cuales podrían estar los asociados calificados.

Tabla 1-: Costos

\begin{tabular}{|c|c|c|c|c|c|}
\hline & \multirow{2}{*}{$\begin{array}{c}1995 \\
\$ \text { COP }\end{array}$} & \multirow[b]{2}{*}{ US $\Phi$} & \multirow[t]{2}{*}{2015} & \multirow[b]{2}{*}{$\$ C O P$} & \multirow[b]{2}{*}{ US $\$$} \\
\hline & & & & & \\
\hline Dólar Dic. 1995 & $\$ 987$ & 1 & Dólar Dic. 2015 & 3.356 & 1 \\
\hline SMLMV 1995 & 118.934 & 121 & SMLMV 2015 & 644.350 & 192 \\
\hline Suelo & 800.000 & 811 & & & \\
\hline Aporte construcción & 2.000 .000 & 2.026 & & & \\
\hline Escritura & 310.000 & 314 & & & \\
\hline Total aporte viviendista & 3.110 .000 & 3.151 & 26 SMLMV & 16.753 .100 & 3.356 \\
\hline Más subsidio & 5.110 .000 & 5.177 & 43 SMLMV & 27.707 .050 & 8.249 \\
\hline Máximo Valor VIP & 8.325 .380 & & 70 SMLMV & 45.104 .500 & 13.440 \\
\hline Diferencia & 3.215 .380 & & 27 SMLMV & 17.397 .450 & 5.184 \\
\hline
\end{tabular}


A valores de 1995; el aporte en efectivo para la construcción representó 2.5 veces más que el realizado para la compra del terreno que pertenecía al Instituto de Crédito Territorial; el precio del suelo representa un poco más del $15,6 \%$ del valor total de la vivienda sin incluir la cuantía que representa la mano de obra aportada por las familias, mediante comités de trabajo en aproximadamente 3 años (en promedio 144 jornadas de 4 horas semanales cada una). La clave de la disminución de los costos, radica en la participación activa de los integrantes de la Asociación, tanto en la administración como en la construcción, pues to que al no existir ánimo de lucro no pueden existir utilidades y todos los recursos deben invertirse en el desarrollo del proyecto

El valor de los aportes en efectivo de los viviendistas (realizado mayoritariamente a partir de créditos) representa 26 salarios mínimos mensuales; si se compara el precio total de la vivienda incluyendo el subsidio, con el máximo de una VIP (70 SMLMV), esta es superior en 27 salarios, es decir una cantidad similar al aportado por cada familia. Si se suma el número de horas aportadas por los viviendistas, estas representarían 72 días de trabajo, es decir aproximadamente 2.5 meses, si cada mes se remunerara sobre un salario mínimo, el ahorro por familia sería de casi 25 salarios mensuales, con respecto al de una VIP.

Los recursos fueron aportados por las familias fundamentalmente a través de créditos con dos entidades financieras cooperativas, una de estas, fundada por los mismos integrantes de ASOVIVIR, denominada CREAR Cooperativa, la cual se constituyó a partir de los aportes de los afiliados. Siendo una entidad del sector solidario, las utilidades deben redistribuirse entre los afiliados o invertidos en lo que estos decidan, estos rendimientos se aportaron para el desarrollo del proyecto, disminuyendo el valor del aporte individual para cada una de las familias.

Como estrategia financiera también se constituyó una fábrica de materiales prefabricados que disminuyó los costos de construcción, estos materiales fueron empleados en el proyecto y dependiendo de la demanda podría continuar produciendo elementos necesarios para el desarrollo progresivo de las viviendas y financiarse a través de CREAR Para complementar los recursos correspondientes a los costos del proyecto, para cada uno de los afiliados de ASOVIVIR, la organización gestionó los subsidios de vivienda.

El proyecto cuya ejecución se llevó tres años permitió la entrega de vivienda a bajo costo, y se convirtió en referente para la localidad e inclusive recibió reconocimientos nacionales como el Primer Puesto, del Concurso TECHO COLMENA, en Vivienda de Interés Social, Categoría Asociativa 1996. El valor del premio se invirtió en la construcción de 50 casas más que se vendieron a precio comercial y el dinero se reinvirtió en el proyecto.

\subsection{Gestión social}

El diseño y construcción del barrio se realizó de manera participativa con el acompañamiento de un equipo de profesionales de la construcción y de la gestión social, la Asociación designó a una persona exclusivamente para el componente de gestión social, encargada de la formulación e implementación de estrategias para la integración de las familias; todas las actividades se desarrollaban dentro de las jornadas de trabajo cada fin de semana, a través de unos comités de trabajo establecidos a partir de las necesidades de los participantes de las jornadas.

Las jornadas fundamentalmente estaban previstas para llevar a cabo actividades no calificadas como el descapote del terreno, la realización de las "chambas" para la colocación de las bases de las casas o la preparación y organización de los materiales para el trabajo de los obreros calificados durante el transcurso de la semana; el trabajo se organizó por cuadrillas especializadas en frentes de obra, estas actividades debían ser desarrolladas de manera obligatoria por un solo integrante de la familia, sin embargo dado que estas se realizaban los domingos normalmente acudía toda la familia, incluidos niños y adultos mayores, estas jornadas devinieron en el desarrollo de múltiples actividades. Estas actividades eran orientadas por diferentes comités de trabajo que fortalecieron el tejido social para la toma de decisiones frente a la administración del proyecto.

Los comités surgían de manera orgánica, por ejemplo, dado que en el desarrollo de cualquier obra de infraestructura existe el riesgo de accidentes, fue necesario implementar un comité de salud para atender a los obreros y a las personas acompañantes, a través de este comité se implementaron programas de atención y prevención con las entidades de salud, que además de desarrollar formación a los integrantes del comité 
desarrollaban campañas extendidas a toda la comunidad., entre estas las deportivas, que luego fueron asumidas por el comité de deportes el cual organizaba torneos de microfútbol en la jornada y al finalizar esta.

Para la información a la comunidad de las actividades y procesos se implementó un sistema de comunicación basado en un micrófono amplificado a través de cornetas, el cual fue complementado con un reproductor de música y otros micrófonos para variar voces y colocar música para evitar la monotonía. Este sistema se convirtió en el comité de comunicaciones, el cual de manera rudimentaria desarrollaba programas de radio para acompañar las jornadas e incluso narraba los partidos organizados por el comité de deportes.

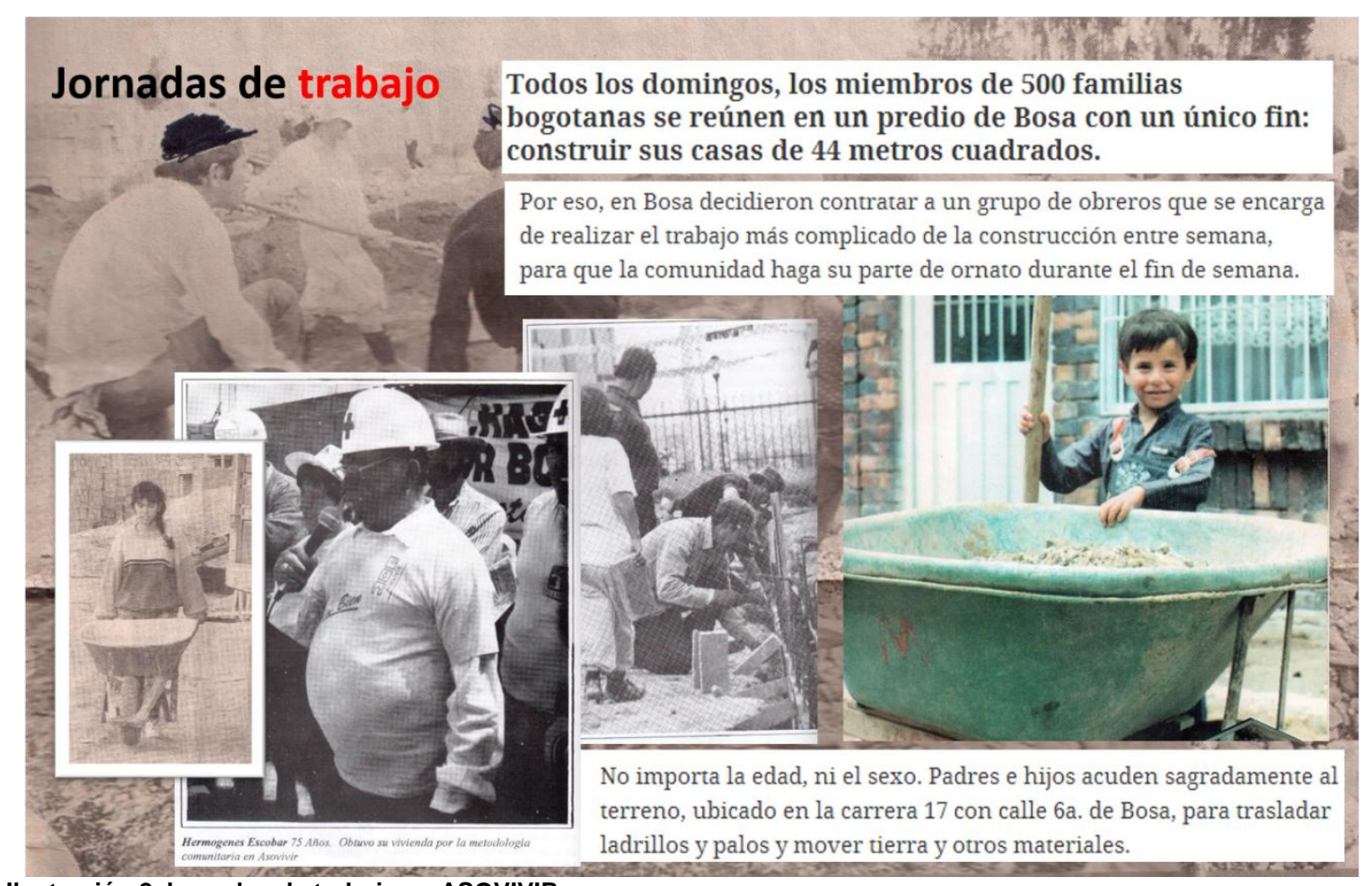

Ilustración 2 Jornadas de trabajo en ASOVIVIR

Elaboración propia a partir de fotos particulares y eltiempo.com, 25 de noviembre de 1996

Como la mayoría de las mujeres llevaban a sus hijos pues no había con quien dejarlos, fue necesario organizar un grupo de personas que se encargaran de cuidarlos durante la jornada y ofrecerles actividades lúdicas para mantenerlos entretenidos o acompañar la realización de tareas, así surgió el comité de infancia. En el proceso de construcción se generaban desechos que debían ser tratados adecuadamente a partir de esto surgió el comité ambiental, que además se encargó del manejo de las zonas verdes, aun hoy algunos vecinos salen los fines de semana a arreglar los jardines de la urbanización.

Dentro de estos comités (se conformaron 26) participaban todos los integrantes de las familias, desde niños hasta adultos mayores, las tareas de estos comités, además del trabajo material de construcción, apuntaba a construir comunidad, y a partir de estos se constituyeron organizaciones aún vigentes como el jardín Infantil ASOVIVITO, producto del comité de infancia y que hoy presta servicio a los niños y niñas del barrio y del sector. El comité de comunicaciones acompañó otros procesos de FENAVIP e incluso se amplió el trabajo a la comunicación escrita, mediante revistas y periódicos para los proyectos de otras OPV. Una vez concluido el proceso de construcción colectiva, el comité de salud se convirtió en una institución prestadora de servicios de salud en la cual pudieron trabajar de manera remunerada algunas personas de la comunidad

Las jornadas de trabajo además de disminuir costos de construcción, contribuyeron a la construcción de comunidad y la apropiación de las viviendas, muestra de ello es que a la fecha más del $70 \%$ de los habitantes son los propietarios originales y no ha ocurrido como en otros proyectos, que una vez transcurrida la restricción de cinco años para vender, e incluso antes, se enajenan los inmuebles. El laboratorio social en que se convirtió 
el desarrollo del proyecto permitió el surgimiento de líderes y lideresas que posteriormente desempeñaron cargos públicos, inclusive de relevancia nacional; Josué Gastelbondo uno de los integrantes de la organización fue viceministro de vivienda en la administración del presidente Álvaro Uribe Vélez y hoy en funcionario de ONU Hábitat; otros asociados se han desempeñado en la administración de Bogotá como secretarios de despacho de la Alcaldía Mayor (entre estas la Secretaría de Integración Social, la Caja de Vivienda Popular y la gerencia de METROVIVIENDA, banco de tierras del Distrito), dos concejales de la ciudad, dos alcaldes y tres ediles locales.

\subsection{Condiciones urbanísticas del proyecto}

La gestión en ASOVIVIR permitió integrar procesos de planeación formal con la posibilidad de desarrollo progresivo de las unidades de vivienda, característico de proceso informales, pudiendo conciliar esta pulsión entre la formalidad y la informalidad. Como lo fija la normatividad, el proyecto se desarrolló en un predio sin riegos, con acceso a servicios públicos y cumpliendo todas las obligaciones de las autoridades respectivas, dado que el predio está ubicado en una zona urbana, está circundado por vías vehiculares de la malla vial local, que son utilizadas por el servicio de transporte público, incluso una de estas vías divide el lote en dos y atraviesa el barrio, con lo cual los habitantes acceden con facilidad a las rutas que los comunican con el resto de la ciudad.

La mayor parte de las vías internas son de carácter peatonal, con lo cual se pudo aprovechar más el terreno disponible y se minimizaron costos de construcción, aunque estas vías se entregaron sin capa asfáltica o concreto, producto de la organización de los vecinos se logró la construcción de estas. Dos vías vehiculares correspondientes a la malla vial local también fueron entregadas sin construir pero producto de la gestión con la Alcaldía Local en cabeza de una ex integrante de la organización, se pudieron desarrollar.

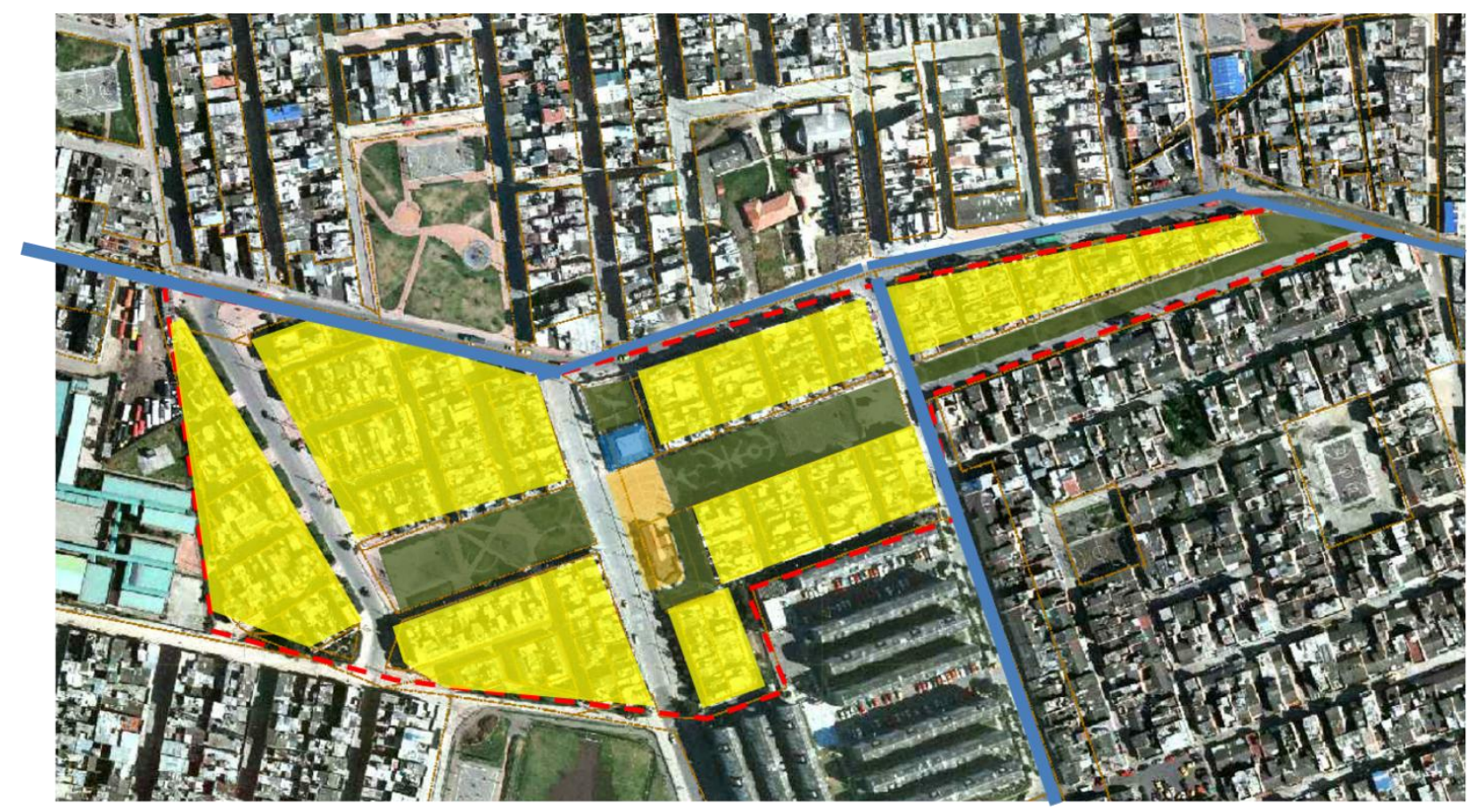

550 unidades de vivienda unifamiliar en lotes de $44 \mathrm{~m}^{2}$ de 1 a 4 plantas

- Ruta Transporte Público (Urbano, Alimentadores, SITP)

$\checkmark$ Jardín Infantil SISD Z Zona comunal Zonas verdes

Ilustración 3 Forma urbana ASOVIVIR.

Fuente elaboración propia sobre google eart

Las 500 casas iniciales desarrolladas cada una en un lote de 44 metros cuadrados, fueron entregadas como unidad básica, ladrillo a la vista, piso afinado, puntos de energía e hidráulicos así como batería sanitaria instalados, con cubierta de teja en asbesto cemento y si la familia realizaba un pago adicional recibía su casa con placa fundida en concreto lista para la ampliación de una segunda planta. Con acceso a los servicios públicos 
básicos de energía, acueducto y alcantarillado y disponibilidad de servicio telefónico y de gas natural, el pago de la instalación de estos dos últimos estaba a cargo de los propietarios

Además de la cesión de los espacios, se entregaron dos edificios dotacionales construidos: El salón comunal y el jardín infantil ASOVIVITO que presta servicio a los habitantes del entorno más allá del barrio. Una buena proporción del predio se destinó a zonas verdes, una franja que atraviesa la urbanización de oriente a occidente genera conectividad ambiental, contribuyendo a bajar el déficit de zonas verdes en la localidad; en medio de la zona verde se ubicaron dos canchas deportivas múltiples. Uno de los principales logros de ASOVIVIR fue la generación de espacio público y zonas verdes, en lo cual la localidad presentaba la mayor falencia del Distrito.

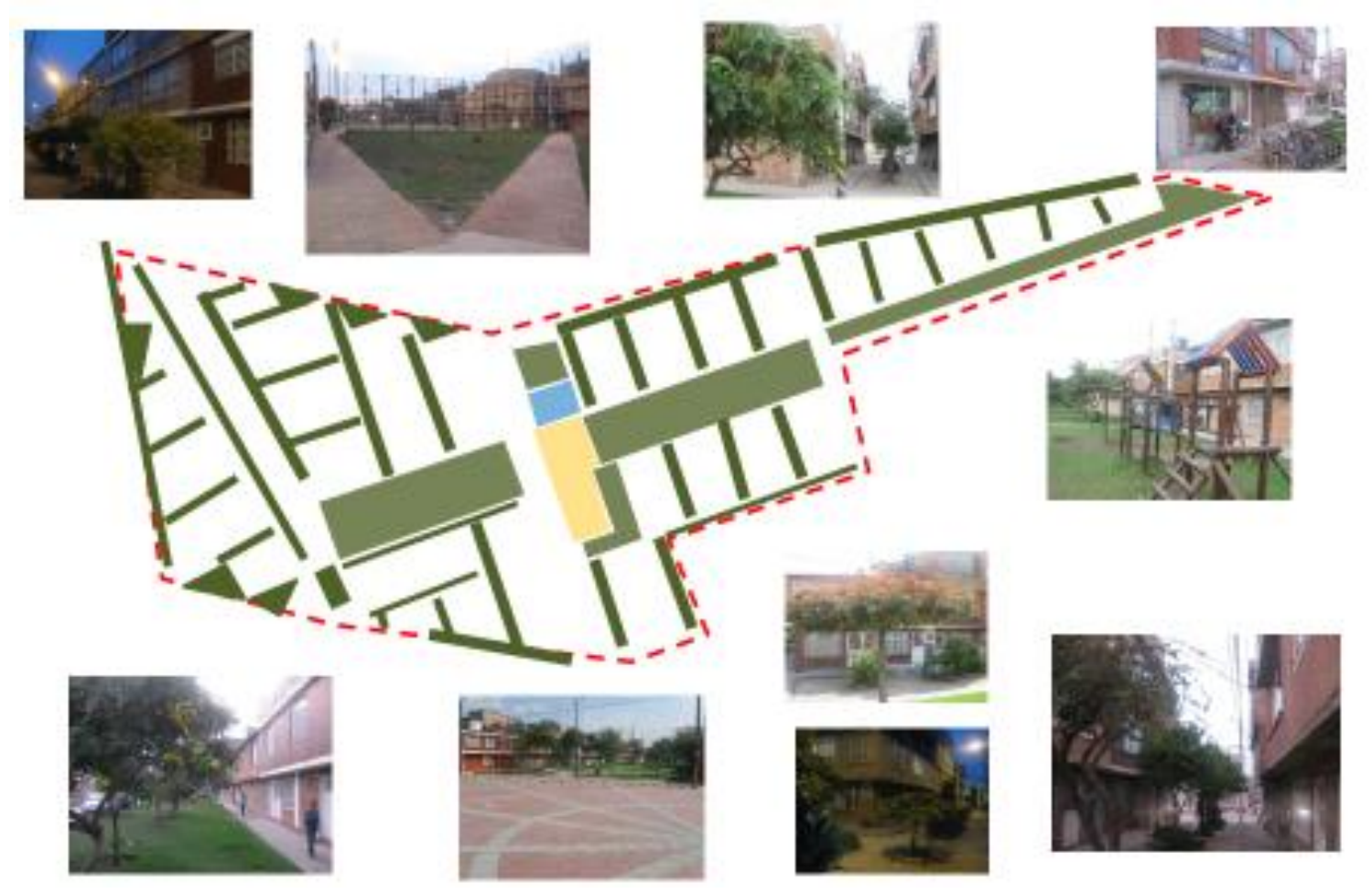

Ilustración 4 Zonas verdes espacio público y dotacionales

Actualmente la urbanización está consolidada así como su entorno, que ofrece una excelente oferta de servicios dotacionales, empleo y recreativo. En la ilustración No. 5 se muestra el entorno de la urbanización, con círculos amarillos los dotacionales (la mayoría son colegios públicos), con círculos blancos las zonas de concentración de empleo (industria y servicios) y con verde los parques y zonas verdes.

Al momento de desarrollar el proyecto existían dos colegios públicos cercanos, el Fernando Mazuera a dos cuadras, el cual fue posteriormente ampliado y remodelado para dar cabida a 7 mil estudiantes en tres jornadas; también estaba el Porfirio Barba Jacob a cinco cuadras con capacidad para cuatro mil estudiantes en dos jornadas. En un lote contiguo a la urbanización se construyó otro colegio público con capacidad para 5 mil estudiantes en dos jornadas. Además de estos hay tres colegios de carácter privado construidos desde mediados del siglo XX como colegios campestres administrados por comunidades religiosas entre estas los Claretianos.

Dentro de los dotacionales también se encuentran en un radio inferior a diez cuadras (mil metros) tres parques públicos multifuncionales administrados por el gobierno distrital y las instalaciones de la alcaldía local en el centro de la localidad, donde además está la capilla doctrinera patrimonio histórico y la plaza fundacional.

Con respecto a las zonas de servicios, comercio y empleo, con círculo en blanco se localizan dos empresas que ofrecen empleo a la gente de la localidad en las cuales están vinculados algunos habitantes de ASOVIVIR. En Piamonte urbanización contigua desarrollada por el ICT, se ubica la mayor zona de concentración de comercio. 
La participación de los viviendistas en el diseño urbanístico y de las unidades habitacionales, permitió desarrollar viviendas adecuadas en el marco del pacto DESC, especialmente en la adecuación cultural, pues se tuvieron en cuenta las necesidades de los futuros habitantes, contemplando el desarrollo progresivo para ampliar las edificaciones de acuerdo con el crecimiento de la familia o para generar renta mediante el arrendamiento de parte de la vivienda. La posibilidad de hacer productiva la casa mediante la renta o la instalación de pequeños establecimientos de comercio, generan sustentabilidad económica para las familias.

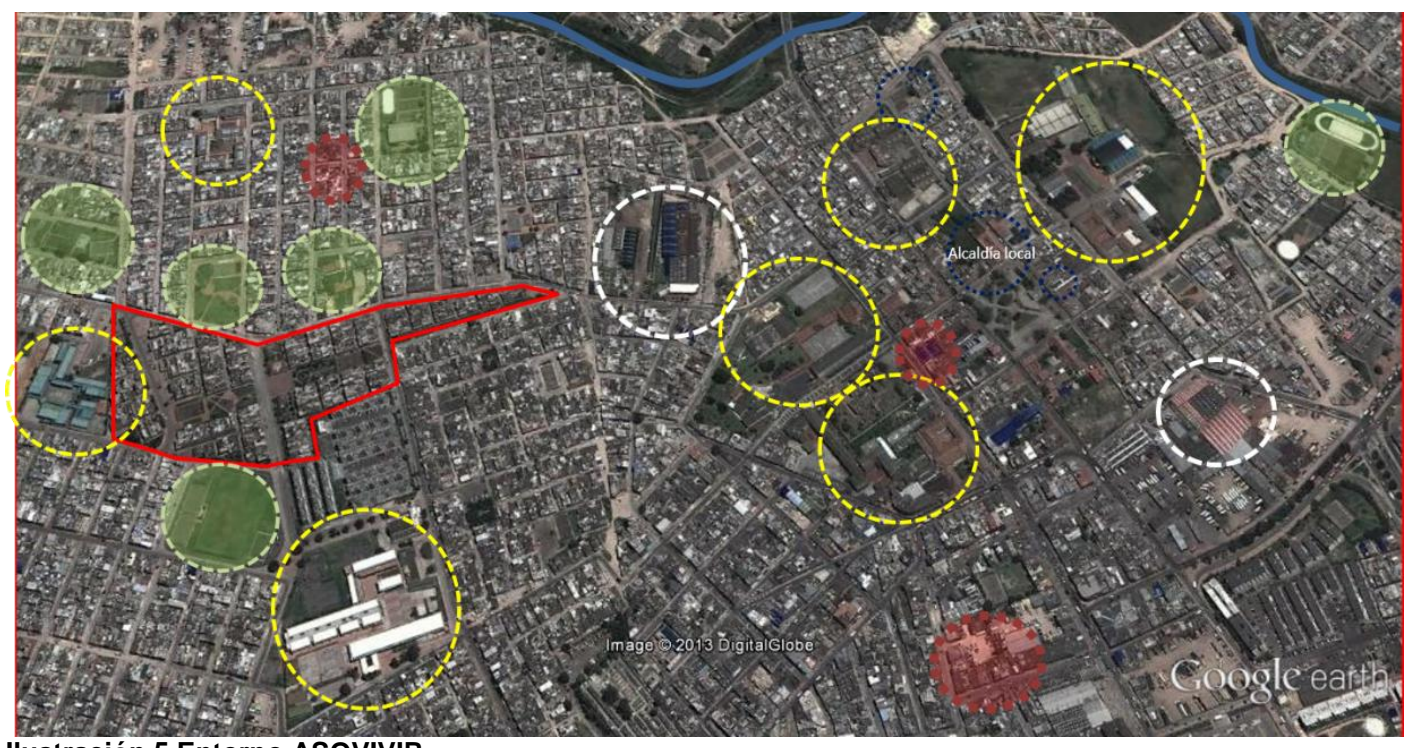

llustración 5 Entorno ASOVIVIR

Fuente elaboración propia sobre google eart

\section{EVALUACIÓN DE LAS DIFICULTADES Y POTENCIALIDADES DEL MISN CIUDAD VERDE}

Ciudad Verde en Soacha es el macroproyecto, que a Octubre de 2016, más unidades habitacionales ha construido en Colombia, es uno de los cinco de iniciativa privada, y aunque con su potencial de 49.656 soluciones de vivienda y un área bruta de 327,96 hectáreas, no es el más grande, es el segundo en tamaño después de Ciudad del Bicentenario en Cartagena (con un área bruta de 388,04 hectáreas y un potencial de 65.138 soluciones de vivienda), fue adoptado en el 2009, un año después de los cuatro primeros, sin embargo es el más avanzado en obras de urbanismo y de viviendas. Fue formulado en 2007 y anunciado en el 2008 para 22.000 soluciones en un polígono de 327,96 Hectáreas; adoptado en 2009 para 36.000 viviendas, la mitad de las cuales serían VIS y VIP; su construcción inició en el 2010 y se proyectó a nueve años, en ese año fue ajustado; en el 2015 nuevamente fue ajustado proyectándose a 49.000 unidades habitacionales y al 2016 aún se encuentra en ejecución. Con el incremento de las unidades habitacionales sin aumentar el suelo la relación de espacios públicos y dotacionales se cambia, además de la proporción de vivienda para familias de menores ingresos, pues los proyectos más recientes por su precio son accesibles para población de mayores ingresos.

Con corte a 31 de agosto de 2016 el Ministerio de Vivienda reporta que este MISN presenta un urbanismo adelantado para 40.564 soluciones de vivienda y en ejecución para 7.592; con 25.220 viviendas terminadas y entregadas, además de 22.936 en ejecución. En comparación los MISN han entregado en Medellín 8.642 viviendas, Cartagena 3.431 y en Palmira (otro MISN de iniciativa privada) 3.289 unidades. El Macroproyecto es de iniciativa privada aunque las entidades públicas pueden efectuar, inversiones públicas en la ejecución, es así como el gobierno nacional asignó 768 cupos de para damnificados por el fenómeno de la niña 2010-2011, por valor de \$13.496,27 millones el cual se pagó a los constructores.

EI MVDT concibe a Ciudad Verde como una operación estratégica a gran escala, que contribuya a la formación de un modelo regional que equilibre la generación de espacio público adecuado en Soacha y dentro de su área de influencia pues permitiría la conectividad Soacha-Bogotá a través de las Avenidas Terreros y Ciudad de Cali 
(que al 2016 aún no se ha construido). Se concibe a CV como una solución al déficit, que asegura la demanda para los gestores del proyecto. Según el Ministerio de Vivienda, Ciudad Verde participa con el 26\% del total de viviendas que se construyen en el país bajo la modalidad de macroproyectos, es una de las más grandes operaciones de vivienda urbana (tiene un área casi un tercio mayor que la de Ciudad Salitre que tiene $250 \mathrm{Has}$.) y la que presenta la mayor dinámica de construcción, en cinco años ha vendido 22.500 unidades y construido $13.940 \mathrm{~m}^{2}$. (MVCT, 2014:69).

Inicialmente se planteó en la Resolución 1687 del 3 de Septiembre de 2009, que el proyecto buscaba "Suplir la demanda de Vivienda de Interés Social del Municipio de Soacha, y aportar en la Disminución del déficit de vivienda existente en el Distrito de Bogotá. Para estos efectos, se generarán por lo menos veintidós mil (22.000) unidades de vivienda." Sin embargo en la misma Resolución se refiere en las solicitudes del Alcalde de Soacha la cifra de 36.000 viviendas y a través de otras modificaciones se ha incrementado a 49.000 viviendas, que con un promedio de 4 personas por hogar, correspondería a unos 196.000 habitantes, con lo cual casi que se incrementaría en aproximadamente el $50 \%$, la cifra de 398.295 soachunos contabilizados en el censo del 2005.

En el Considerando de la resolución de adopción se expresa claramente que debido a la localización del Macroproyecto "obliga a realizar el análisis del déficit cuantitativo, incluyendo la ciudad de Bogotá, que según el Censo del 2005 es de 243.652 hogares que representan el 12,6 \% de 1.931.372 hogares existentes en la ciudad de Bogotá D.C. para 2005". La localización de este proyecto obedece más a criterios económicos que a necesidades de ordenamiento municipal, pues esta área no estaba considerada como de expansión urbana en el Plan de Ordenamiento Territorial de Soacha. Se puede observar la relación del área de Ciudad Verde con respecto al casco urbano de Soacha, del cual está más lejos que de la zona urbanizada en la localidad de Bosa en Bogotá, separado solo por el Canal del Tibanica

Ciudad Verde representa un incremento del 23,5\% del área de Soacha, que según el DTS de la revisión del POT 2006-2007, es de 2699 has. de las cuales solamente 1392 has. estaban urbanizadas ${ }^{3}$; este macroproyecto representa para Soacha un cambio significativo en sus horizontes de planeación e inversión, rompe con su patrón de desarrollo informal, (como ocurrió con Bosa y la intervención de METROVIVIENDA a principios del siglo XXI) implica la ampliación de responsabilidades sociales y administrativas para las cuales el gobierno municipal no estaba preparado, pues aún tiene un déficit en la atención de sus habitantes, además con el cambio de patrón de uso de industrial a residencial, se pierden fuentes de empleo y de desarrollo para la población.

Ciudad Verde representa un incremento del 23,5\% del área de Soacha, que según el DTS de la revisión del POT 2006-2007, es de 2699 hectareas, de las cuales solamente 1392 has. estaban urbanizadas ${ }^{4}$; este macroproyecto representa para Soacha un cambio significativo en sus horizontes de planeación e inversión, rompe con su patrón de desarrollo informal, (como ocurrió con Bosa y la intervención de METROVIVIENDA a principios del siglo XXI) implica la ampliación de responsabilidades sociales y administrativas para las cuales el gobierno municipal no estaba preparado, pues aún tiene un déficit en la atención de sus habitantes, además con el cambio de patrón de uso de industrial a residencial, se pierden fuentes de empleo y de desarrollo para la población.

\footnotetext{
${ }^{3}$ Ver página institucional del municipio http://www.soacha-cundinamarca.gov.co/informacion_general.shtml\#geografia

${ }^{4}$ Ver página institucional del municipio http://www.soacha-cundinamarca.gov.co/informacion_general.shtml\#geografia
} 


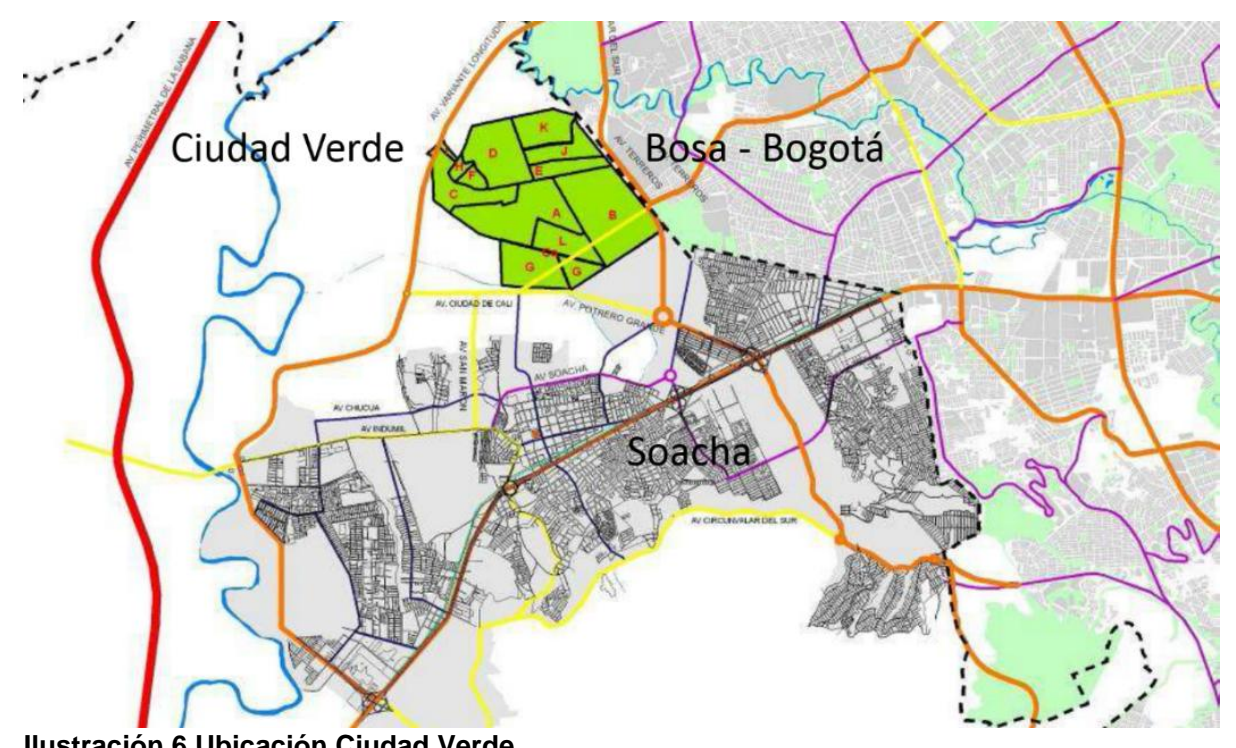

Ilustración 6 Ubicación Ciudad Verde

Elaboración propia a partir de plano de Amarilo S.A.

La conectividad es un aspecto que fue tenido en cuenta por los promotores del proyecto, tal como lo evidencia la siguiente ilustración, los predios están circundados de vías proyectadas de carácter regional que conectan con otras arterias como la Autopista Sur y la Longitudinal de Occidente.

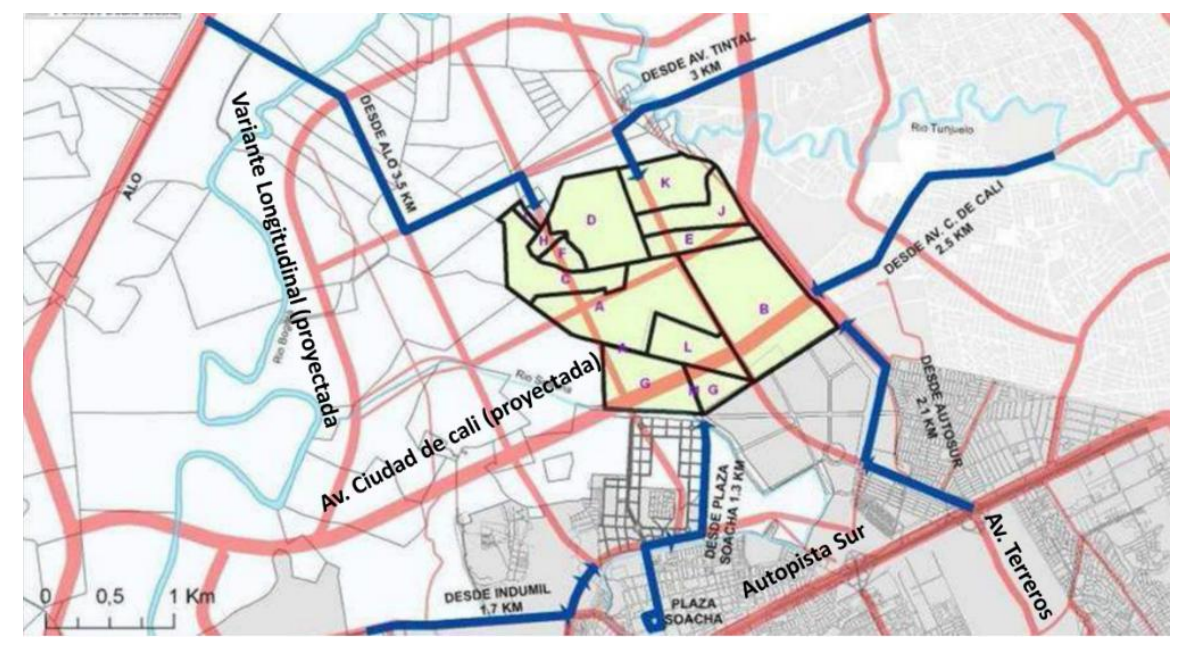

Ilustración 7 Accesibilidad vial

Elaboración propia a partir de plano de Amarilo S.A.

\subsection{El marco normativo, jurídico y político}

Al momento del anuncio, adopción y ejecución del MSIN Ciudad Verde, estaba vigente el Plan de Ordenamiento Territorial de Soacha, aprobado por el Acuerdo 46 del 2000, el cual contempla el territorio donde se desarrolla CV como zona rural; incluso el artículo 376 del Acuerdo define como áreas inundables el sector noroccidental de Soacha, (dentro de las cuales se ubica el Macroproyecto) y la restricción de densidad a máximo 20 viviendas por hectárea sobre área útil, pues "cuentan con afectación por riesgo por inundación y/o carecen de los servicios públicos". Del territorio donde se desarrolla CV, el POT del 2000 solo contempla como zona de expansión urbana, la franja del costado noroccidental de la proyectada Avenida Ciudad de Cali, incluso el ordenamiento territorial contemplaba un Parque Metropolitano en límites con el Humedal Tibanica y uno de los tres "Parques Bosques de la Tranquilidad" en la zona de preservación ambiental y patrimonial que se incorpora al Macroproyecto. Esta zona de "Conservación y desarrollo sostenible de la explotación agropecuaria intensiva, en suelos no inundables, que mantenga una franja agrícola entre cascos urbanos de Bogotá y Soacha" (Acuerdo 046 Articulo 19) 
En el POT se señala que hay déficit de cupos escolares (55\% para primaria y secundaria y $85 \%$ para pre-escolar) que es cubierto en parte por Bogotá, se plantea además que el porcentaje de la población soachuna que trabaja en Bogotá es del $55 \%$, (esto califica a Soacha como ciudad dormitorio), a partir de estas condiciones, se prioriza en el ordenamiento territorial la generación de zonas industriales como fuentes de empleo, transformando zonas rurales para proyectos industriales como el de Vidrio Andino, lo cual es objetado por la autoridad ambiental, Corporación Autónoma Regional - CAR, que reclama los asuntos ambientales acordados con el municipio durante la etapa de evaluación y concertación y que no fueron incorporados en el acuerdo 046 del 27 de diciembre de 2000. Varios de los servicios públicos, como la energía eléctrica, el acueducto y alcantarillado son prestados por empresas de Bogotá; las redes matrices y secundarias de aguas potable y servida, fueron construidas en su mayoría por los urbanizadores, pero el servicio es prestado por la Empresa de Acueducto de Bogotá.

De otra parte en Bogotá se ajusta el POT mediante el Decreto 190 de 2004, que fija dentro de los Objetivos, vincular la planeación del Distrito Capital al Sistema de Planeación Regional, por lo cual determina:

"Detener los procesos de conurbación mediante el control de la expansión urbana, un manejo concertado de los usos del suelo en el Distrito y la Región en áreas periféricas a los nodos urbanos, a las zonas de influencia del sistema movilidad, y mediante la articulación de las políticas y proyectos de servicios públicos a las directrices de planificación regional" (Artículo 1, numerales 3 y 4)

"Áreas de actuación estratégica en el marco de una agenda regional: - Vivienda y equipamientos. Promoción de acciones y proyectos integrales de vivienda, servicios y actividades económicas, que fortalezcan las ventajas competitivas y el ordenamiento de las ciudades de la red y que promuevan el mejoramiento de su funcionalidad y calidad urbana." (Artículo 4, numeral 5.)

Antes de la adopción del Macroproyecto, a través del Acuerdo 018 del 2008, se aprueba el Plan de Desarrollo de Soacha 2008-2011 "Soacha para Vivir Mejor", el cual reconoce que en el Municipio hay concentración de familias de bajos recursos con "altos índices de necesidades básicas insatisfechas reflejados en la calidad de la vivienda y en la inexistencia de algún servicio básico." Además que debido al origen informal de la mayoría de la vivienda hay problemas con las seguridad jurídica de la tenencia "especialmente en las áreas adyacentes a zonas de fuerte crecimiento urbano de Bogotá, las zonas de Altos de Cazucá y Ciudadela Sucre en el área nororiental del municipio y del desborde de Bosa y Kennedy en el noroccidente" así como inexistencia de espacios públicos en estos territorios. El Plan también reconoce que una tercera parte de Soacha presenta amenaza por fallas geológicas, deslizamientos e inundaciones y la vivienda está "localizada en zonas altamente degradadas o en condiciones de riesgo, que obligan al gobierno municipal a emprender procesos de desalojo y reubicación, con los costos implícitos que ello conlleva." Otro problema evidenciado es la migración hacia el municipio y plantea "la necesidad de localizar población de Bogotá en sus áreas aledañas, dado las tasas de crecimiento poblacional de la urbe y a que en la ciudad capital no existe suelo urbano para su localización." (Acuerdo 018 del 2008)

El déficit cuantitativo para Soacha al momento de la formulación del Plan de Desarrollo (2008) se calculaba en 13.868 viviendas, mientras que "alrededor del $20 \%$ del parque habitacional con que cuenta, que representa cerca de 17.553 viviendas, tiene deficiencias cualitativas y 20.649 hogares viven en condiciones de hacinamiento, entre crítico y moderado, lo que pone de presente que la política habitacional del municipio no puede centrarse exclusivamente en vivienda nueva, sino también en una política integral que promueva el mejoramiento tanto de la vivienda como del hábitat en su conjunto." (Acuerdo 018 del 2008) Con el potencial de CV se podría entonces atender el déficit cuantitativo de Soacha y quedaría un excedente de más de 22.000 viviendas para Bogotá.

En el mismo Acuerdo 018 se consigna que "Una de las mayores falencias en el municipio es espacio público de encuentro y esparcimiento y los existentes son pocos y no presentan las condiciones para ser espacios verdes que cumplan una labor ecológica, social y paisajística, por lo cual se requiere trabajar en su embellecimiento y arborización." Pues apenas hay $1,9 \mathrm{~m}^{2}$ de zonas verdes y $12 \mathrm{~m}^{2}$ de espacios peatonales por habitante. La oferta de CV respondería a esta falencia.

Con el Acuerdo 308 del Junio 9 de 2008 se adopta el "Plan de Desarrollo Económico, Social, Ambiental y de Obras Públicas para Bogotá, D. C., 2008 - 2012 Bogotá Positiva: Para Vivir Mejor"; este Plan se estructura en varios ejes, siendo uno de estos el de Ciudad Global que contiene a su vez varios programas, el primero de estos denominado Región Capital, que busca consolidar la Región Capital "como un territorio planeado e integrado en 
lo físico, económico, social, cultural, fiscal y ambiental, aprovechando las fortalezas y oportunidades de cada territorio". El otro programa de este Eje es el del Río Bogotá el cual pretende: "Adelantar acciones integrales, entre el sector público, el sector privado y la comunidad, y articuladas con la Región Capital y la Nación, que permitan la defensa, recuperación, protección y adecuado aprovechamiento de la cuenca del Río." En las metas para el Proyecto Hábitat Región del Plan se señala específicamente: "Habilitar 214 hectáreas con troncales de acueducto y alcantarillado en el Macroproyecto Soacha" y "Generar 20.000 VIS a través del Macroproyecto Soacha Aunque no había sido anunciado aun el MISN de Soacha, el Plan ya lo contemplaba.

Adicionalmente la Ordenanza Departamental No. 009 del 11 de Junio de 2008 "Por la cual se adopta el plan departamental de desarrollo 2008 -2012 Cundinamarca Corazón de Colombia", en el subprograma "Nuevos techos para la equidad" señala: "se apoyará y promoverá, de manera concertada y en coordinación con la Región Capital, el desarrollo de macroproyectos de vivienda y modelos de habitabilidad tipo Ciudad Salitre", fijando como metas promover y gestionar el desarrollo de dos macroproyectos.

Se evidencia articulación y coincidencia entre la administración nacional y las municipales en cuanto al número de unidades, y coincidencia política frente a los macroproyectos con la administración departamental; los planes fueron aprobados en Junio de 2008, antes del anuncio del Macroproyecto en Septiembre del mismo año, lo cual evidencia el interés por la integración regional, que es complementada por intervenciones integrales de movilidad, como la extensión de la Troncal Norte-Quito-Sur del Sistema Transmilenio, que potencializa la formulación del Macroproyecto Ciudad Verde, el cual fue presentado públicamente a través de la Resolución de Anuncio y Delimitación No.1577 de Septiembre del 2008, posteriormente fue adoptado mediante Resolución No.1687 del 3 de Septiembre de 2009, modificada por las Resoluciones No. 1434 del 27 de Julio de 2010, No.1355 del 6 de Julio de 2011 y No.0182 del 20 de Marzo de 2015.

El Plan Nacional de Desarrollo 2010 -2014 (Ley 1469 de 2011), en su Artículo $132^{\circ}$ plantea dentro de los Lineamientos Estratégicos a Nivel Regional: "Reactivación de macro proyectos urbanos de vivienda y gestión concertada Nación - Entidades Territoriales: mayor equilibrio regional alrededor de la vivienda, la provisión de agua potable y saneamiento", y el desarrollo de sistemas de movilidad, para el cumplimiento de la meta de construcción de un millón de viviendas (que se fijó a través del Decreto 1310 del 14 junio de 2012). El Plan también contempla dos ejes estratégicos de infraestructura vial nacional que confluyen en Soacha: El Transmilenio sobre la Autopista Sur y el transporte de carga sobre la ALO y la Avenida Circunvalar del Sur.

Transmilenio es el principal eje de transporte público para el desplazamiento entre lugares de empleo y habitación entre Soacha y Bogotá, así se facilita la estructuración del Área de Desarrollo Territorial de Bogotá y su región metropolitana, que se concreta con la adopción de la Región Administrativa y de Planeación Especial -RAPE entre Bogotá y Cundinamarca y otros Departamentos. La RAPE faculta al nivel departamental para: "Establecer directrices y orientaciones para el ordenamiento de la totalidad o porciones específicas de su territorio, especialmente en áreas de conurbación con el fin de determinar los escenarios de uso y ocupación del espacio, de acuerdo con el potencial óptimo del ambiente y en función de los objetivos de desarrollo, potencialidades y limitantes biofísicos, económicos y culturales". (Artículo 29, Ley 1469 de 2011).

\section{Gestión económica de las familias adquirientes}

Con el fin de indagar sobre los procesos sociales al interior de CV, como parte del proyecto de investigación "Macroproyectos de Interés Social Nacional: La tensión entre la política nacional de vivienda y el ordenamiento territorial municipal. Caso MISN Ciudad Verde Soacha" y en el marco del curso Vivienda Social en Colombia dirigido por el profesor Carlos Torres de la facultad de Artes en la Universidad Nacional, con los estudiantes participantes del curso se realizó un trabajo de campo que se dividió en dos facetas, una de corte cuantitativo, con la aplicación de un instrumento de investigación a modo encuesta, en 95 unidades habitacionales previamente definidas a partir de muestro aleatorio. Así mismo se desarrolló una faceta cualitativa, con la aplicación de cerca de 40 encuestas a actores públicos, privados y comunitarios.

La encuesta compuesta por 170 preguntas, organizadas en 10 secciones, las dos primeras dedicadas a la identificación predial y a la caracterización demográfica, las ocho restantes correspondientes a las variables de la vivienda adecuada del PIDESC; la unidad de análisis son los hogares y tomando por objetivo sus características habitacional. 
Un aspecto que se contempló en las encuestas y que es pertinente de incluir en el análisis de la gestión económica, es la relacionada con los costos que implican para las familias la adquisición y mantenimiento de sus viviendas, es decir si se cumple la condición de gastos soportables que aseguren el derecho a una vivienda adecuada de acuerdo con el PIDESC. El primer aspecto de la indagación gira sobre los ingresos en los hogares de la ciudadela, medidos en términos de SLMMV del año 2014 (\$616.000) en pesos colombianos. La mayoría de los hogares no superan un ingreso de 2 SMMLV, lo cual los hace acreedores del subsidio para VIP, pero no les permitiría cubrir adecuadamente los gastos de la familia y la vivienda.

\begin{tabular}{|c|c|c|c|c|c|}
\hline 1-2 SMMLV & 1 SMMLV o menos & 2-3 SMMLV & 3-4 SAMMLV & +4 SLMMLV & No responde \\
\hline $50 \%$ & $19.6 \%$ & $18.5 \%$ & $8.7 \%$ & $1.1 \%$ & $2.2 \%$ \\
\hline
\end{tabular}

Tabla 2 Ingresos familiares CV

Fuente: elaboración propia con base a la encuesta elaborada en el año 2014

Con respecto a las condiciones de financiamiento y subsidio para el acceso a la vivienda, no se establecen los montos económicos, por cuestiones de confidencialidad y reserva al momento del trabajo de campo. Se indagó por las fuentes del subsidio con el siguiente panorama:

\begin{tabular}{|c|c|c|c|c|}
\hline Caja de Compensación & No recibió/Otros & Municipio Bogotá & Gobierno Central & Municipio Soacha \\
\hline $50.5 \%$ & $37.9 \%$ & $6.3 \%$ & $3.2 \%$ & $2.1 \%$ \\
\hline
\end{tabular}

Tabla 3 Fuente del subsidio familiar de vivienda

Se observa el alto porcentaje de las Cajas de Compensación Familiar en la asignación de subsidios, lo cual podría explicarse por la participación de Colsubsidio en la Fiducia, que le permitiría canalizar las subvenciones hacia sus afiliados, y esta participación evidencia la condición de empleados formales de los habitantes del Macroproyecto.

Todas las viviendas de CV por su precio son de Interés Social o de Interés Prioritario, es decir sus adquirientes tiene derecho al subsidio familiar de vivienda, a menos que posean inmuebles a su nombre, por eso es significativo que el $37,9 \%$ de los hogares encuestados no optaron por subsidios, lo cual evidencia que en este Macroproyecto participan personas que seguramente adquirieron los apartamentos como un segunda vivienda en calidad de inversión y esto explica la alta oferta de inmuebles en arriendo.

Dado que la mayoría de las familias no recibieron subsidio por el valor total del apartamento (el valor del subsidio para familias con ingresos de dos SMLMV era en el 2014 de $\$ 11.704 .000$ ) y para efectos del cierre financiero debieron recurrir a créditos. Al valor de la cuota mensual del crédito, se deben sumarse los costos de servicios públicos, para evaluar cuál es el saldo para el sostenimiento del grupo familiar. A valores del 2014, si las familias reciben dos salarios mínimos mensuales $(\$ 1.232 .000)$ y a esto se le resta el pago de los servicios y la cuota del crédito, queda disponible un valor de $\$ 640.385$, para el sostenimiento de la familia, es decir que en los gastos de la vivienda corresponden a casi la mitad de los ingresos de una familia promedio de CV. A estos costos se deben sumar el valor de las adecuaciones habitacionales que corren por cuenta de los nuevos propietarios, las cuales son necesarias en la medida que la mayoría de las viviendas se entrega sin los acabados completos.

Para familias que devengan menores ingresos, la situación es más crítica, las encuestas nos revelan que un $28.1 \%$ de las familias están en mora con los pagos de Mantenimiento de Áreas verdes y Recolección de Basura de la ciudadela y que un $20,6 \%$ de los hogares se encuentra en mora con las cuotas de la administración, coincidiendo con familias que tienen un ingreso mensual igual o menor de un SMLMV, la falta de pago de la administración de acuerdo con la Ley de propiedad horizontal podría desencadenar en embargo, sin embargo la vivienda social es inembargable, pero estas deudas afectan el equilibrio económico de las familias y si es masivo puede afectar el mantenimiento y pago de servicios de las zonas comunes.

\subsection{Gestión social}

Dado que las familias adquieren sus inmuebles ya terminados, la gestión social inicia con la llegada a sus apartamentos, siendo un gran desafío la convivencia de personas de diversos orígenes y condiciones culturales, algunas de las cuales nunca habían vivido en conjuntos residenciales de propiedad horizontal. La organización de la ciudadela es por conjuntos residenciales, a los cuales llegan las familias de manera escalonada, de acuerdo 
con los avances de las obras, esto genera un fraccionamiento en los procesos organizativos pues al interior de cada conjunto existe un consejo de administración encargado de atender los problemas al interior de estos.

Los espacios colectivos de encuentro de los habitantes de los conjuntos se reducen normalmente a las asambleas, que son generalmente anuales, en las cuales se elige el consejo de administración y el administrador, a los cuales se les delega la gestión del mantenimiento y "gobierno" del conjunto. La relación de las personas con la administración se reduce fundamentalmente a una relación comercial, en la cual las familias pagan por los servicios públicos colectivos y el mantenimiento de las zonas comunes a una persona o una empresa a quien se le delega la tarea de administrar.

Los promotores de CV han impulsado la organización de una instancia de participación a través de la cual se pretende articular los diferentes conjuntos para la gestión colectiva de la ciudadela, siendo una de las tareas fundamentales de esta instancia, el mantenimiento de las zonas comunes y espacios públicos del Macroproyecto, para lo cual se cobra una cuota a cada una de las familias de la ciudadela.

Las encuestas realizadas en el marco del curso Vivienda Social en Colombia dirigido por el profesor Carlos Torres, permiten evaluar algunos aspectos sobre la gestión social. El 92,7\% de los hogares no se auto-identifica dentro de la población vulnerable; tan sólo el 5.3\% de la población se reconoce como desplazados del conflicto armado, y $2 \%$ como afectados por fenómenos ambientales, especialmente por la ola invernal de 2010 en los barrios Cazucá y San Mateo de Soacha

Tal como se observa en la siguiente tabla, el 58,9\% de los hogares cuenta con 3 o 4 integrantes por unidad habitacional, se puede observar la preponderancia de familias nucleares, y llama la atención la existencia de hogares de un solo miembro. A pesar que CV es producto de un proceso de planificación formal, aunque relativamente bajo, se evidencia hacinamiento, ya que el 15,9\% de las viviendas cuenta con 5 o más habitantes; por ahora, se revela la preponderancia de una sola familia nuclear por vivienda, lo cual se corrobora con la existencia de una sola cocina en la vivienda

\begin{tabular}{|c|c|c|c|c|c|c|c|}
\hline 1 & 2 & 3 & 4 & 5 & 6 & 7 & 8 \\
\hline $4.2 \%$ & $21 \%$ & $28.4 \%$ & $30.5 \%$ & $11.6 \%$ & $1.1 \%$ & $2.1 \%$ & $1.1 \%$ \\
\hline
\end{tabular}

Tabla 4 Habitantes por vivienda

Llama la atención que el $26.3 \%$ de los hogares encuestados son arrendatarios, con lo cual se está violando la restricción legal para la vivienda social y da cuenta que un porcentaje de esta no está asignada a quienes realmente la necesitan para suplir su déficit cuantitativo, esto puede ser ratificado con la evidencia que el $19 \%$ de los hogares eran propietarios previos y podrían haber adquirido la vivienda como inversión o para suplir déficit cualitativo. Aquí se reproduce el mercado de arrendamiento informal, ya no es legal optar por un contrato de arrendamiento o venta en VIS y VIP en un tiempo inferior a 5 años de su entrega; de esta manera sentido se vulnera completamente la protección legal contra el desahucio, aspecto incorporado en el PIDESC.

\section{Tabla 5 Condición de tenencia de la vivienda}

\begin{tabular}{|c|c|c|}
\hline Allegado & Arrendatario & Propietario \\
\hline $2.1 \%$ & $26.3 \%$ & $71.6 \%$ \\
\hline
\end{tabular}

El trabajo de campo reveló que no existen instancias institucionales de participación con la comunidad habitante del Municipio para la planeación y desarrollo del Macroproyecto, de acuerdo con la normatividad vigente y especialmente para este MISN de iniciativa privada, solo se establece concertación entre los actores públicos y privados, sin consulta alguna de la comunidad ni de sus instancias de participación como lo expresa la presidenta del Consejo Territorial de Planeación de Soacha

Tampoco hay concertación con los nuevos propietarios frente al futuro de CV, la relación de las constructoras con los usuarios es meramente comercial en torno a los productos inmobiliarios, el status de los habitantes no es de ciudadanos sino de clientes, sujetos demandantes de unidades habitacionales, y por lo tanto, se desarrolla una ciudadela que desconoce las necesidades colectivas de la población; se restringe la posibilidad que la ciudadanía participe de las decisiones de su territorio y la interacción con las autoridades municipales es nula. 
La incipiente organización comunitaria que está surgiendo, es motivada por las carencias de bienes y servicios, por lo tanto la participación posterior a la formulación del proyecto, es reivindicativa frente a los constructores y el gobierno municipal, solicitudes que son canalizadas fundamentalmente a través de las administraciones de los conjuntos. Los Consejos de administración son los principales espacios de participación.

A través del portal web Periodismo Público ${ }^{5}$ la comunidad ha establecido un mecanismo de comunicación, organización y denuncia; el 6 de Mayo del 2013 Ariel González pública un artículo titulado "Los Macroproblemas de Ciudad Verde en Soacha" y a partir de este se ha establecido una conversación virtual a través del cual se denuncian las principales problemáticas que se resumen a continuación. Según González para esta época cerca de diez mil personas de estratos uno y dos habitaban CV.

González anuncia que CV es un notorio fracaso urbanístico, por falencias como la infraestructura vial y el acueducto, la movilidad, la falta de servicio público de transporte, la ausencia de cupos escolares y la alta percepción de inseguridad. El 6 de octubre del mismo año, González publica otro artículo titulado "Preocupación en Ciudad Verde por falta de colegios para niños y adolescentes" en el que se documenta una protesta de la comunidad de CV frente a las instalaciones de Amarilo por el incumpliendo de la oferta de un colegio público para octubre del año 2013, fecha en la que se estima que cerca de 23.000 familias habitan la ciudadela. Esta misma protesta se repitió en el primer trimestre del 2014, reiterando el incumpliendo de la entrega de un colegio público para la ciudadela.

Any carolina se quejaba: "que tristeza siento y que arrepentida me siento en este momento más que en otro de a ver comprado allí, pues le comunico que a hoy julio del 2015 ciudad verde está llena de vendedores ambulantes, en cada esquina una plaza de mercado y parece que familias enteras se están apoderando de los andenes, plazoletas, bancas para sus ventas, osea que nadie ha hecho algo para parar esto AUXILIO!!! Como quién dice los vendedores ambulantes comenzaron al tiempo con ciudad verde, ahora empezaran a exigir se les indemnice, se les pague para entregar lo que es público y que ellos convirtieron en particular que tal !!!!!! En los pocos espacios públicos que aún no están tomados por los vendedores ambulantes se ven muy bonitos, pero donde ya han invadido se ve horrible todo y sucio, da aburrimiento estar allí. GALO DE JESUS plantea que. "Este es un problema de orden social en el cual necesariamente debe intervenir la nación; este es el resultado de la las decisiones apresuradas y mal tomadas por el gobierno nacional de turno en aquella época; Es muy importante que se tomen cartas en el asunto para que esto no se vuelva una bomba de tiempo." Lo cual se complementa con una opinión de alfredo1966, quien escribe así, en mayúsculas: "SE LOGRO EL OBJETIVO: SACAR DE BOGOTÀ LAS FAMILIAS QUE NO PUEDEN APLICAR A UNA VIVIENDA POR FALTA DE CAPACIDAD DE ENDEUDAMIENTO, ESPECULACION DE LA TIERRA Y PRECIOS INFLADOS DE LA VIVIENDA."

Sin embargo otras personas opinan lo contrario, Andres Gallegos escribe: "Después de leer detenidamente todos estos comentarios puedo concluir que cada quien habla de como le halla ido después de ser residente de la ciudadela. He de mencionar en el momento me encuentro pagando la cuota inicial de una de las unidades residenciales de CIUDAD VERDE en el proyecto AZAHAR De OSPINAS a ser entregado en primer trimestre de 2015. Lo unico que tengo para decir es que para tratarse de invertir en finca raiz NO es nada costoso y el macroproyecto tiene mucho futuro. El solo hecho de comprar sobre planos ya es ganancia y mas a estos valores tan comodos aun mas si pensamos en la BURBUJA INMOVILIARIA que se acerca en donde las personas que compraron predios a precios costosos por estar en lugares exclusivos de bogota van a ser los mas perjudicados. A las personas que quieren o piesen invetir en CIUDAD VERDE ya bien sea para habitarlo o arrendarlo o dejarlo quieto entre tanto se valorice !!! HAGALO... no lo piensen mucho. Los inconvenientes de urbanismo se iran solucionando por el camino, nadie ha dicho que sea facil, pero la satisfaccion de vivir en un inmueble propio NO TIENE PRECIO. Es evidente que Adres Gallegos, piensa en inversión, no en satisfacción de una necesidad, desde la perspectiva económica sustentada en la especulación y la valorización la política de vivienda es efectiva.

Queda la duda sobre el criterio que tiene el señor Gallegos después de haber recibido su inmueble, si es que lo habitó o simplemente lo dejo "quieto entre tanto se valorice", mientras tanto algunos habitantes de la ciudadela siguen inconformes y se están organizando; a través de perfil de facebook.com ${ }^{6}$ Ciudad Verde Promesas

\footnotetext{
${ }^{5}$ Ver: Los Macroproblemas de Ciudad Verde http://periodismopublico.com/Los-Macroproblemas-de-Ciudad-Verde

${ }^{6}$ Ver en https://www.facebook.com/CiudadVerdePromesasIncumplidas/
} 
Incumplidas se comparte la publicación de Veeduría Ciudad Verde el 19 de septiembre de 2016 que convoca: "cansados ya de tantas promesas y problemas en materia de movilidad, transporte público, colegios, hospitales, estación de policía, falta del servicio de agua, estratificacion exagerada, pagos elevados de servicio público, corte de cesped, ventas ambulantes, grafitis, consumo de drogas, construcciones sin licencia y malos manejos de la agrupación social y administradores de conjuntos que han desvalorizado sus propiedades y llevado a muchos a vender en lo que se prometía era la solución de vivienda digna para la inversión del patrimonio familiar."

María Mercedes Maldonado, secretaria de Hábitat en el gobierno de Bogotá 2012-2015, expresa el 21 de Octubre de 2016, en la Universidad Nacional de Colombia en la Conferencia ¿Qué viene después de Hábitat III?, que los MISN son una negación del derecho a la ciudad, se han desarrollado como una negocio en el cual las pequeñas constructoras y las OPV no pueden participar por falta de experiencia y capital. Plantea como ejemplo a Ciudad Verde, donde según ella hay menos del $20 \%$ en VIP y el colegio que "regalo" la constructora es un problema para la administración local pues el municipio no puede asumir los costos de funcionamiento. Los MISN efectivamente no satisfacen el derecho a una vivienda adecuada, mientras la gestión a través de las OPV se convierte en una opción para satisfacer las necesidades particulares de quienes construyen vivienda a la medida

\section{BIBLIOGRAFIA}

CHOAY, Francoise. Urbanismo Utopías y Realidades. Barcelona. Lumen. 1970

CORTE CONSTITUCIONAL COLOMBIANA Sentencia T-583/13 Disponible en: http://www.corteconstitucional.gov.co/RELATORIA/2013/T-583-13.htm

DEPARTAMENTO NACIONAL DE PLANEACIÓN, REPUBLICA DE COLOMBIA

Planes Nacionales de Desarrollo 2006-2010, 2010-2014 y 2014-2018

Documento CONPES No. 3583. Lineamientos de política y consolidación de los instrumentos para la habilitación de suelo y generación de oferta de vivienda Ministerio de Ambiente, Vivienda y Desarrollo Territorial DNP Bogotá D.C., 2009

FARHA, Leilani. Informe de la Relatora Especial sobre una vivienda adecuada como elemento integrante del derecho a un nivel de vida adecuado y sobre el derecho de no discriminación a este respecto. Naciones Unidas Asamblea General 30 de diciembre de 2015. \{En línea\}. $\{10$ abril de 2016\} disponible en: (https://documents-dds-ny.un.org/doc/UNDOC/GEN/G15/294/55/PDF/G1529455.pdf?OpenElement)

HALL, Peter. Ciudades del mañana. Historia del urbanismo en el siglo XX. Barcelona: Ediciones del Serbal, 1996. $495 \mathrm{p}$.

HARVEY, David. Urbanismo y desigualdad social. Madrid: Siglo Veintiuno Editores, 1977

Ciudades rebeldes. Del derecho a la ciudad a la revolución urbana. Madrid: Akal. 2013.

Diecisiete contradicciones y el fin del capitalismo $1^{\text {a }}$ ed. Quito: Editorial IAEN. 2014

JARAMILLO, Samuel. Producción de vivienda y capitalismo dependiente. El caso de Bogotá. Editorial Dintel. 1979. 240p

Las formas de producción del espacio construido en Bogotá. En Pradilla Cobos, E. (Com). Ensayos sobre el Problema de la Vivienda en América Latina. México DF: Universidad Autónoma Metropolitana Unidad Xochimilco, 1982, p. 149-212.

MINISTERIO DE AMBIENTE, VIVIENDA Y DESARROLLO TERRITORIAL.

Decreto 4260 (2007) Por medio del cual se reglamenta el Artículo 79 de la Ley 1151 de 2007

Resolución 1577 (2008). "Por medio de la cual se anuncia, por motivos de utilidad pública e interés social, el Macroproyecto de Interés Social Nacional Ciudad Verde del municipio de Soacha departamento de Cundinamarca."

Resolución 0318 (2009). "Por medio de la cual se adiciona la Resolución número 1577 del 10 de septiembre de 2008"

Resolución 1687 (2009). "Por medio del cual se adopta, por motivos de utilidad pública e interés social, el Macroproyecto de Interés Social Nacional Ciudad Verde en el Municipio de Soacha, Cundinamarca"

Resolución 1434 (2010). Por medio del cual se modifica y adiciona la Resolución 1687

Resolución 1355 (2011). Por medio del cual se modifica y adiciona la Resolución 1434

MINISTERIO DE VIVIENDA CIUDAD Y TERRITORIO Cien años de política habitacional en Colombia. Bogotá: Panamericana. 2014. 280p

\footnotetext{
${ }^{7}$ Ver en https://www.facebook.com/groups/veeduriaciudadverde/?fref=nf
} 
MUNICIPIO DE SOACHA. Acuerdo 18 del 31 de mayo de 2008 - Plan de desarrollo municipal de Soacha 20082011- Soacha para vivir mejor.

ONU Comité de Derechos Económicos, Sociales y Culturales. Observación General No. 4. Sexto período de sesiones, 1991. Disponible en www.observatoriopoliticasocial.org

ONU Hábitat. El derecho humano a una vivienda adecuada Folleto informativo sobre los derechos humanos № 21 (Rev.1). Geneva. Oficina del alto comisionado de las Naciones Unidas para los derechos humanos. 2010 disponible en http://www.ohchr.org

Estado de las ciudades de América Latina y el Caribe. Brasil: CAF - Banco de desarrollo de América Latina, agosto del 2012. $243 p$

Construcción de ciudades más equitativas. Bogotá: CAF - Banco de desarrollo de América Latina, marzo 2014. $243 p$

Habitat III Zero Draft Outcome Document. Disponible en: http://www.worldurbancampaign.org/sites/default/files/Habitat\%20III\%20Zero\%20Draft\%20outcome\%20doc ument\%20\%28May\%202016\%29_0.pdf (May 2016).

ORTIZ FLORES, Enrique. Producción social de la vivienda y el hábitat. Montevideo, Hábitat International Coalition, 2012

PRADILLA COBOS, Emilio.

Autoconstrucción, explotación de la fuerza de trabajo y políticas de Estado en América Latina. En Ensayos sobre el problema de la vivienda en América Latina, Emiliano Pradilla. México: UAM - Xochimilco. 1982.

Capital, Estado y Vivienda en América Latina. Cap. I. Notas acerca del problema de la vivienda. México: Fontamara, 1987.

SALDARRIAGA ROA, Alberto. Estado, ciudad y vivienda. Urbanismo y arquitectura de la vivienda estatal en Colombia, 1918-1990. Bogotá: INURBE, 1996.

TORRES TOVAR, Carlos... [et al]. Pobreza urbana y mejoramiento integral de barrios: hábitat y vivienda. Bogotá: Universidad Nacional de Colombia. Facultad de Artes, 2009. 392 p.

TORRES TOVAR, Carlos Alberto y CASTILLO DE HERRERA Mercedes. Procesos urbanos informales y territorio: ensayos en torno a la construcción de sociedad, territorio y ciudad. Grupo de investigación Procesos urbanos en hábitat, vivienda e informalidad. Bogotá: Universidad Nacional de Colombia. Facultad de Artes. Maestría en Hábitat. 2009.

TURNER, John. Libertad para construir: el proceso habitacional controlado por el usuario. México: Siglo XXI Editores. 1976 